\title{
The Mechanism and Kinetics of Propene Ammoxidation over $\alpha$-Bismuth
}

\section{Molybdate}

\author{
Rachel B. Licht, Diana Vogt and Alexis T. Bell* \\ Department of Chemical and Biomolecular Engineering \\ University of California \\ Berkeley, CA 94720-1462 \\ and \\ Chemical Sciences Division \\ Lawrence Berkeley National Laboratory \\ Berkeley, CA 94720
}

Submitted to

Journal of Catalysis

January 17, 2016

*Author to whom correspondence should be addressed: alexbell@berkeley.edu 


\begin{abstract}
Propene ammoxidation over $\mathrm{Bi}_{2} \mathrm{Mo}_{3} \mathrm{O}_{12}$ was investigated to elucidate product (acrylonitrile, acetonitrile, $\mathrm{HCN}$, acrolein, $\mathrm{N}_{2}$, etc.) formation pathways. Propene consumption rate is first order in propene and zero order in ammonia (for $\mathrm{NH}_{3} / \mathrm{C}_{3} \mathrm{H}_{6}=0$-2) and oxygen (for $\left.\mathrm{O}_{2} / \mathrm{C}_{3} \mathrm{H}_{6} \geq 1.5\right)$ partial pressures, with an activation energy $\left(\mathrm{E}_{\mathrm{a}}=22 \mathrm{kcal} / \mathrm{mol}\right)$ comparable to that for propene oxidation, suggesting the same rate-limiting step for both reactions. We propose two $\mathrm{N}$-containing species are relevant at ammoxidation conditions: adsorbed $\mathrm{NH}_{3}$ on surface $\mathrm{Bi}^{3+}$ ions that reacts with a propene derivative to form products with $\mathrm{C}-\mathrm{N}$ bonds, and a few metastable $\mathrm{M}-\mathrm{NH}_{\mathrm{x}}(\mathrm{M}=\mathrm{Mo}, \mathrm{Bi} ; \mathrm{x}=1,2)$ groups that are very sensitive to destruction by water, but that are responsible for $\mathrm{NH}_{3}$ oxidation to $\mathrm{N}_{2}$. A proposed reaction mechanism and model that captures the experimental trends in product distribution as a function of partial pressures and temperature is presented.
\end{abstract}

Keywords: Bismuth molybdate, selective ammoxidation, propene, ammonia, acrylonitrile 


\section{Introduction}

Bismuth molybdate-based catalysts have been used extensively since their discovery in the 1950s by SOHIO to perform important oxidation and ammoxidation reactions of light olefins [1]. The most industrially relevant of these processes is the ammoxidation of propene to acrylonitrile, which had a worldwide demand of over 10 billion pounds per year in 2012 [2]. Almost half of the acrylonitrile produced is used to make acrylic fibers for textiles, with the remainder either polymerized to make plastics (ABS, SAN, NBR, etc.) or further reacted to small molecules such as acrylamide or adiponitrile. Two commercially important byproducts are also produced and recovered from propene ammoxidation, namely acetonitrile and hydrogen cyanide $(\mathrm{HCN})$. Since the primary product desired from propene ammoxidation is acrylonitrile, catalyst development efforts have led to a steady rise in acrylonitrile yield from $\sim 55 \%$ for bismuth molybdate to $>80 \%$ for current industrial catalysts that contain approximately ten metal elements, including bismuth and molybdenum [3].

Given the importance of propene ammoxidation, considerable effort has been devoted to understanding this reaction and the related oxidation of propene to acrolein. Much of this work has been conducted with the distorted scheelite $\alpha-\mathrm{Bi}_{2} \mathrm{Mo}_{3} \mathrm{O}_{12}$ phase [4] because of its good catalytic activity and its structural similarity to ternary metal oxides such as $\mathrm{Bi}_{1-\mathrm{x} / 3} \mathrm{~V}_{1-\mathrm{x}} \mathrm{Mo}_{\mathrm{x}} \mathrm{O}_{4}$, $\mathrm{Bi}_{3} \mathrm{FeMo}_{2} \mathrm{O}_{12}, \mathrm{Bi}_{2} \mathrm{Mo}_{2.5} \mathrm{~W}_{0.5} \mathrm{O}_{12}$ and $\mathrm{Bi}_{2-\mathrm{x}} \mathrm{Ce}_{\mathrm{x}} \mathrm{Mo}_{3} \mathrm{O}_{12}$ that have been reported to have higher catalytic activity [5,6,7]. Research has shown that both $\mathrm{Bi}$ and Mo are needed to catalyze these reactions; for example, $\mathrm{MoO}_{3}$ will not react propene, but will form acrolein or acrylonitrile from allyl radicals generated in situ $[8,9]$. By contrast, $\mathrm{Bi}_{2} \mathrm{O}_{3}$ will slowly activate propene, but will only form hexadiene [10]. Since the initial steps of propene ammoxidation are thought to be similar, or identical, to those of propene oxidation to acrolein, and the product of the latter 
reaction is also observed during propene ammoxidation, it is useful to first summarize what is known about propene oxidation over bismuth molybdate.

Studies of propene oxidation over bismuth molybdate using deuterated propene reveal that the rate-limiting step is hydrogen abstraction from the methyl group of propene $[11,12]$. Historically, this step has been thought to occur on an oxygen atom associated with bismuth $[13,14,15]$; however, recent work by our group demonstrates that a molybdenyl oxygen perturbed by a neighboring bismuth atom is the most likely site for propene activation [16]. Further experiments with isotopically labeled carbon demonstrate that this first step generates a physisorbed, symmetric allyl [17,18], most likely with radical character [19]. ${ }^{18} \mathrm{O}_{2}$ labeling studies have shown that the $\mathrm{O}$ in the product acrolein comes from the catalyst surface via a Marsvan Krevelen mechanism [20,21]. It has been hypothesized that acrolein is formed by addition of the allyl radical to a surface molybdenyl oxo $(\mathrm{Mo}=\mathrm{O})$ group to form a Mo-bound allyl alkoxide, which then undergoes hydrogen abstraction to produce acrolein [22]. The two abstracted hydrogen atoms are released as water during the reoxidation of the catalyst by molecular oxygen, thereby completing the overall reaction. It is noted that molecular $\mathrm{O}_{2}$ is not directly involved in the formation of acrolein, and that propene oxidation can occur for a period of time in the absence of gas-phase $\mathrm{O}_{2}$ by reaction of propene with surface oxygen atoms, which are replaced by oxygen atom diffusion from the bulk $[11,23]$.

The steady-state kinetics of propene oxidation, measured in the presence of at least a stoichiometric partial pressure of oxygen, are reported to be first order in propene and zero order in oxygen. Acrolein formation is generally observed to have an activation energy of $\sim 20$ $\mathrm{kcal} / \mathrm{mol}$, though values between 17 and $31 \mathrm{kcal} / \mathrm{mol}$ have been reported $[5,21,24,25,26]$. The 
primary byproducts of propene oxidation are $\mathrm{CO}, \mathrm{CO}_{2}$, and acetaldehyde, though trace amounts of acetic acid, acetone, acrylic acid and ethene have also been observed.

Propene ammoxidation to acrylonitrile $\left(\mathrm{CH}_{3}-\mathrm{CH}=\mathrm{CH}_{2}+\mathrm{NH}_{3}+{ }^{3} / 2 \mathrm{O}_{2} \rightarrow \mathrm{CH}_{2}=\mathrm{CH}-\mathrm{CN}+\right.$ $\left.3 \mathrm{H}_{2} \mathrm{O}\right)$ is a more complex reaction than propene oxidation $\left(\mathrm{CH}_{3}-\mathrm{CH}=\mathrm{CH}_{2}+\mathrm{O}_{2} \rightarrow \mathrm{CH}_{2}=\mathrm{CH}-\right.$ $\mathrm{CHO}+\mathrm{H}_{2} \mathrm{O}$ ), and is accompanied by the formation of acetonitrile, hydrogen cyanide, propionitrile and $\mathrm{N}_{2}$, in addition to $\mathrm{CO}_{x}$, acrolein and $\mathrm{H}_{2} \mathrm{O}$. Nevertheless, several features of these two reactions are similar. First of all, the apparent activation energy for acrylonitrile formation is the same as for acrolein formation $(\sim 20 \mathrm{kcal} / \mathrm{mol})$, as are the partial pressure dependencies (first order in propene pressure and zero order in oxygen and ammonia, as long as ammonia and oxygen are supplied in at least stoichiometric quantities) $[27,28,29]$. Second, isotopic labeling experiments indicate that the rate-limiting step for propene ammoxidation again involves the initial abstraction of a hydrogen atom from the methyl group of propene [30]. These observations suggest that propene activation occurs at the same catalyst surface site for both reactions. Third, in the absence of gas-phase oxygen, the catalyst will temporarily convert propene to acrylonitrile if ammonia is present, indicating that, again, activation of propene and subsequent hydrogen removal steps involve oxygen atoms that are part of the catalyst structure $[31,32]$.

Details of the mechanism of propene ammoxidation following the initial activation of propene activation are poorly understood. In particular, the mechanism by which the acrylonitrile $\mathrm{C}-\mathrm{N}$ bond is formed remains a topic of speculation. Interestingly, it has been observed that there is very little $\mathrm{C}-\mathrm{O}$ bond formation to make acrolein when ammonia is fed, despite all other conditions being favorable for propene oxidation [27,28]. While the reaction of acrolein and ammonia to form acrylonitrile is extremely facile $\left(\mathrm{E}_{\mathrm{a}}=\sim 7 \mathrm{kcal} / \mathrm{mol}\right)$, multiple researchers have 
concluded from experiments at short contact times that the majority of the acrylonitrile formed during propene ammoxidation does not proceed through acrolein as an intermediate $[27,28]$. Therefore, the direct reaction of propene to acrylonitrile must be favored kinetically, as well as thermodynamically, over the reaction of propene to acrolein.

The most prevalent hypothesis for $\mathrm{C}-\mathrm{N}$ bond formation involves reaction of allyl species with surface $\mathrm{Mo}=\mathrm{NH}$ groups, followed by three hydrogen abstractions of the resulting surface species. This mechanism, proposed by Grasselli et al. [13], is appealing because it parallels the mechanism generally accepted for propene oxidation (see above). These authors also observed that the ratio of acrylonitrile to acrolein for conditions where $\mathrm{NH}_{3} / \mathrm{C}_{3} \mathrm{H}_{6}<1$ increases linearly with $\left(\mathrm{NH}_{3}\right)^{2} / \mathrm{C}_{3} \mathrm{H}_{6}$ for most reaction conditions [33], from which they concluded that a surface $\mathrm{NH}=\mathrm{Mo}=\mathrm{NH}$ species requiring $2 \mathrm{NH}_{3}$ molecules to form is the primary $\mathrm{C}-\mathrm{N}$ bond formation site. It is noted though, that no experimental evidence for $\mathrm{Mo}=\mathrm{NH}$ groups on the surface of $\mathrm{Bi}_{2} \mathrm{Mo}_{3} \mathrm{O}_{12}$ has been reported in the literature.

Recent DFT calculations carried out on $\mathrm{MoO}_{2} \mathrm{Cl}_{2}$ clusters show that the Gibbs free energy of reaction at $673 \mathrm{~K}$ of $\mathrm{O}=\mathrm{Mo}^{6+}=\mathrm{O}$ species and $\mathrm{NH}_{3}$ to produce $\mathrm{H}_{2} \mathrm{O}$ and $\mathrm{O}=\mathrm{Mo}^{6+}=\mathrm{NH}$ species is $+12.4 \mathrm{kcal} / \mathrm{mol}$, and that the formation of $\mathrm{HN}=\mathrm{Mo}^{6+}=\mathrm{NH}$ species is even further uphill $(+27.8 \mathrm{kcal} / \mathrm{mol}$ from the fully oxidized site) [34]. These very unfavorable thermodynamics for formation of $\mathrm{Mo}=\mathrm{NH}$ groups suggests that in the presence of water, produced as a byproduct of propene ammoxidation (> 3 mol $\mathrm{H}_{2} \mathrm{O}$ produced / $\mathrm{mol} \mathrm{C}_{3} \mathrm{H}_{6}$ consumed), the surface concentration of $\mathrm{Mo}=\mathrm{NH}$ groups should be very small. The instability to hydrolytic decomposition in air at room temperature of $\mathrm{Mo}^{6+}=\mathrm{NR}$ groups in organometallic complexes has also been reported $[35,36,37]$. We note further that theoretical calculations of the transition state enthalpy change for the reaction of an allyl species with a $\mathrm{Mo}_{3} \mathrm{O}_{9}$ cluster to produce bound acrolein is 10.9 
$\mathrm{kcal} / \mathrm{mol}$ [38], and the transition state enthalpy change for the reaction of allyl species with a $\mathrm{Mo}_{3} \mathrm{O}_{8} \mathrm{NH}$ cluster to produce bound acrylonitrile is very similar at $11.4 \mathrm{kcal} / \mathrm{mol}$ [39]. Together, this evidence suggests that the surface concentration of $\mathrm{Mo}=\mathrm{NH}$ groups relative to $\mathrm{Mo}=\mathrm{O}$ groups on the surface of $\mathrm{Bi}_{2} \mathrm{Mo}_{3} \mathrm{O}_{12}$ is likely to be very low, and therefore the former groups are unlikely to be responsible for the observed high selectivity to acrylonitrile during propene ammoxidation.

Several alternatives to $\mathrm{Mo}=\mathrm{NH}$ groups have been investigated as possibly catalytically relevant species. Wragg et al. found there was no experimental evidence to support involvement of $\mathrm{NO}$ or $\mathrm{N}_{2} \mathrm{O}$ intermediates during propene ammoxidation [28]. In an investigation of $\mathrm{NH}_{3}$ adsorption and decomposition over $\mathrm{Bi}_{2} \mathrm{MoO}_{6}$, Matsuura observed two modes of adsorption: a weak $\sigma$-bonding interaction with a metal cation $\left(\Delta H_{a d s}=-6.2 \mathrm{kcal} / \mathrm{mol}\right)$ and a strong dissociative chemisorption ( $\Delta \mathrm{H}_{\mathrm{ads}}=-24 \mathrm{kcal} / \mathrm{mol}$ ) [40]. He proposed that the latter mode of adsorption would result in the formation of $\mathrm{Bi}=\mathrm{NH}$ groups that might combine to form $\mathrm{N}_{2}\left(\mathrm{E}_{\mathrm{a}}=\right.$ $37 \mathrm{kcal} / \mathrm{mol}$ ) or react with coordinated allyl species to form acrylonitrile.

The aim of the present study was to explore the mechanism and kinetics of propene ammoxidation, with the particular goal of shedding new light on the processes involved in the formation of the $\mathrm{C}-\mathrm{N}$ bond appearing in acrylonitrile and in the nitrogen-containing byproducts (acetonitrile and $\mathrm{HCN}$ ). A further aim was to identify the extent to which acrolein, the product of propene oxidation, and allylamine might act as intermediates to acrylonitrile. It will be shown that the results of this investigation provide new insights into the reaction pathways involved in the ammoxidation of propene and the factors affecting the utilization of ammonia to form products containing $-\mathrm{CN}$ groups instead of $\mathrm{N}_{2}$. Our work also leads to a comprehensive model for the kinetics of propene ammoxidation over $\mathrm{Bi}_{2} \mathrm{Mo}_{3} \mathrm{O}_{12}$ that properly describes the effects of reactant and product partial pressures and temperature. 


\section{Experimental and Theoretical Methods}

\subsection{Catalyst preparation and characterization}

$\mathrm{Bi}_{2} \mathrm{Mo}_{3} \mathrm{O}_{12}$ was prepared by the method of complexation with citric acid, which produces a solid product with a more uniform distribution of metal atoms and a higher surface area than can be achieved by the method of co-precipitation [41]. Ammonium molybdate tetrahydrate, $\left(\mathrm{NH}_{4}\right)_{6} \mathrm{Mo}_{7} \mathrm{O}_{24} \cdot 4 \mathrm{H}_{2} \mathrm{O},(99.98 \%$ from Sigma-Aldrich) was dissolved in $0.3 \mathrm{M}$ citric acid solution with the ratio 1 citrate: 1 Mo. Bismuth(III) nitrate pentahydrate, $\mathrm{Bi}\left(\mathrm{NO}_{3}\right)_{3} \cdot 5 \mathrm{H}_{2} \mathrm{O},(99.98 \%$ from Sigma-Aldrich) was dissolved in a solution of $2 \mathrm{M} \mathrm{HNO}_{3}$ and $0.2 \mathrm{M}$ citric acid with the ratio 1 citrate: $1 \mathrm{Bi}$. The Mo solution was added slowly to the Bi solution and the resultant mixture was boiled while stirring to remove most of the water. The concentrated solution was dried overnight in air at $333 \mathrm{~K}$ to produce a foam, then calcined in air at $873 \mathrm{~K}$ for $6 \mathrm{~h}$. The as-prepared catalyst was analyzed by powder XRD to confirm the distorted scheelite crystal structure as reported in literature [42]. The surface area of the catalysts was determined to be approximately $1 \mathrm{~m}^{2} / \mathrm{g}$ from the BET isotherm measured at the temperature of liquid nitrogen.

\subsection{Catalyst performance}

Measurements of reaction rates were performed in a packed bed quartz tube reactor with 10-mm diameter. $\mathrm{Bi}_{2} \mathrm{Mo}_{3} \mathrm{O}_{12}$ was diluted with fumed silica and loaded into the reactor. The catalyst was heated to reaction temperature $(603-753 \mathrm{~K})$ at $3 \mathrm{~K} / \mathrm{min}$ under a $20 \mathrm{~mL} / \mathrm{min}$ flow rate of $20 \%$ oxygen diluted in helium, and left overnight at these conditions. All reactions were carried out at atmospheric pressure with $0-12 \%$ propene (Praxair), 0-22\% ammonia (Praxair), 8$19 \%$ oxygen (20\% in helium, Praxair) and balance helium (Praxair). Gas flow rates were controlled by Bronkhorst Mass Flow Controllers (MFCs). A reactor loaded with only fumed silica and treated in the same way as the catalyst did not produce significant quantities of any 
product, and changing the ratio of diluent to catalyst did not affect the active-surface-area-scaled rates. Catalyst loading, reactant partial pressures, and total space velocity were chosen to maintain propene conversion $<5 \%$ so that intrinsic kinetics could be measured under conditions of differential conversion. The catalyst was always stabilized for at least 2 days under ammoxidation conditions (693 K, $7.6 \mathrm{kPa} \mathrm{C}_{3} \mathrm{H}_{6}, 7.9 \mathrm{kPa} \mathrm{NH} 3,15.6 \mathrm{kPa} \mathrm{O}_{2}$ ) before performing measurements of the reaction kinetics.

Products were analyzed by an Agilent 6890 Gas Chromatograph (GC) equipped with a 30-m HP-PLOT Q column attached to a Flame Ionization Detector (FID) and an Alltech Hayesep DB packed column attached to a Thermal Conductivity Detector (TCD). Acetaldehyde, acetone, acetonitrile, acrolein, acrylonitrile, ammonia, ethene, hydrogen cyanide (HCN), propene and propionitrile were analyzed on the FID, while carbon dioxide, carbon monoxide, nitrogen, nitrous oxide and oxygen were analyzed on the TCD. Details of how the GC was calibrated are given in the Supporting Information. Except for the selectivity versus conversion plot, all reported data points are averages of more than three sample injections in the GC. The lines downstream of the reactor were maintained at $\sim 390 \mathrm{~K}$ to prevent water condensation and resulting product polymerization before being introduced to the GC.

Since the reactor was operated under differential conversion conditions, propene conversion was calculated on the basis of products formed by dividing the moles of carbon in all the products by the moles of carbon in the propene reactant feed. Carbon product selectivities were scaled based on the number of carbon atoms in each species according to Eqn. 1, where $a_{i}$ is the number of carbon atoms in product $i$ and $n_{i}$ is the number of moles of product $i$.

$$
\text { C Selectivity }_{i}(\%)=\frac{a_{i} n_{i}}{\sum_{i} a_{i} n_{i}} * 100
$$


Ammonia conversion was similarly calculated by dividing the moles of nitrogen in all the products by the moles of nitrogen in the ammonia reactant feed. Nitrogen product selectivities were calculated based on the number of nitrogen atoms in each species according to Eqn. 2, where $b_{i}$ is the number of nitrogen atoms in product $i$.

$$
N \text { Selectivity } y_{i}(\%)=\frac{b_{i} n_{i}}{\sum_{i} b_{i} n_{i}} * 100
$$

For experiments in which a liquid feed was used, the desired compound was loaded into a syringe and added to the gas feed mixture via syringe pump set at a constant volumetric flow rate. The combined feed with the vaporized compound was then sent to the reactor and analyzed in the same way described above. In the case of acrolein, this compound was diluted 1:1 in hexane in order to prevent acrolein polymerization in the syringe needle. Hexane was verified to not affect the rate of reaction.

\subsection{Theoretical calculations}

Quantum chemical calculations were performed using density functional theory (DFT) in the Q-Chem program. The 6-31G* basis set was used for geometry optimizations and the triple zeta $6-311 \mathrm{G}++\mathrm{G}(3 \mathrm{df}, 3 \mathrm{pd})$ basis set for the final energies, both in conjunction with the $\omega \mathrm{B} 97 \mathrm{X}-\mathrm{D}$ exchange-correlation functional to model all gas phase species. Bond Dissociation Energies (BDEs) were calculated by subtracting the energy of the optimized parent structure from the sum

of the energies of each of the two separately optimized structure fragments resulting from breaking the desired bond. Enthalpy and entropy corrections for the gas phase reaction energies were calculated at $673 \mathrm{~K}$ and 1 atm using the $6-31 \mathrm{G}^{*}$ basis set and the $\omega \mathrm{B} 97 \mathrm{X}-\mathrm{D}$ exchangecorrelation functional.

For the $(\mathrm{O}=\mathrm{Mo}=\mathrm{O})_{2} \mathrm{Bi}_{2} \mathrm{O}_{10} \mathrm{H}_{10}$ model of the proposed active site, the Def2-SVP $(\mathrm{Bi} \&$ Mo) basis set and effective core potential plus the 6-31G* $(\mathrm{O}, \mathrm{N}, \& \mathrm{H})$ basis set were used for 
geometry optimizations, and the Def2-TZVPD (Bi and Mo) plus the 6-311++G(3df, 3pd) (O, N, and $\mathrm{H}$ ) for the final energies, both in conjunction with the B97-D exchange-correlation functional. The parameters for Bi and Mo were obtained from the EMSL basis set exchange. The enthalpy and entropy corrections were calculated using the Grimme Rigid Rotor Harmonic Oscillator method [43] at $673 \mathrm{~K}$ and $1 \mathrm{~atm}$. The entropy loss upon adsorption was calculated with the assumptions of Marin et al. that weakly adsorbed molecules can still rotate in 3-D and translate in 2-D [44]. The $(\mathrm{O}=\mathrm{Mo}=\mathrm{O})_{2} \mathrm{Bi}_{2} \mathrm{O}_{10} \mathrm{H}_{10}$ active site model was built using the optimized (010) surface of $\mathrm{Bi}_{2} \mathrm{Mo}_{3} \mathrm{O}_{12}$ as a reference [45]. See the Supporting Information for more calculation details about the $(\mathrm{O}=\mathrm{Mo}=\mathrm{O})_{2} \mathrm{Bi}_{2} \mathrm{O}_{10} \mathrm{H}_{10}$ model.

\section{Results}

\subsection{Reaction Kinetics}

\subsubsection{Propene and ammonia consumption}

Fig. 1 shows the dependence of the rate of propene consumption on the partial pressures of propene, ammonia and oxygen at low conversion. The rate of propene consumption is first order in propene partial pressure, whether or not ammonia is present. For oxygen partial pressures above stoichiometric $\left(\mathrm{O}_{2} / \mathrm{C}_{3} \mathrm{H}_{6}>1.5\right)$, the rate of propene consumption is zero order in oxygen. The observed reactant partial pressure dependencies are consistent with a Mars-van Krevelen mechanism in which the propene is activated by catalyst oxygen species and catalyst re-oxidation by gas phase oxygen occurs much more rapidly than catalyst reduction by propene, such that the catalyst surface remains fully oxidized. We note, however, that, for a fixed propene partial pressure, as the oxygen partial pressure decreases below approximately stoichiometric $\left(\mathrm{O}_{2} / \mathrm{C}_{3} \mathrm{H}_{6}=1.5\right)$, the rate of propene consumption begins to decrease. This indicates that at low 
oxygen pressures, the rate of catalyst re-oxidation by gas phase oxygen becomes comparable to the rate of catalyst reduction. Fig. 1 also shows that, for a catalyst that has previously been stabilized in ammoxidation conditions, the rate of propene consumption is independent of ammonia partial pressure across the range of $\mathrm{NH}_{3} / \mathrm{C}_{3} \mathrm{H}_{6}$ ratios from 0 to 2 . The reactant partial pressure dependencies reported here for propene consumption are consistent with those reported earlier for acrylonitrile formation $[27,28]$. For an $\mathrm{O}_{2} / \mathrm{C}_{3} \mathrm{H}_{6}$ ratio greater than or equal to 1.5 , this leads to the following rate expression (Eqn. 3) for the consumption of propene.

$$
-r_{C_{3} H_{6}}=k_{R L S} P_{C 3 H 6}
$$
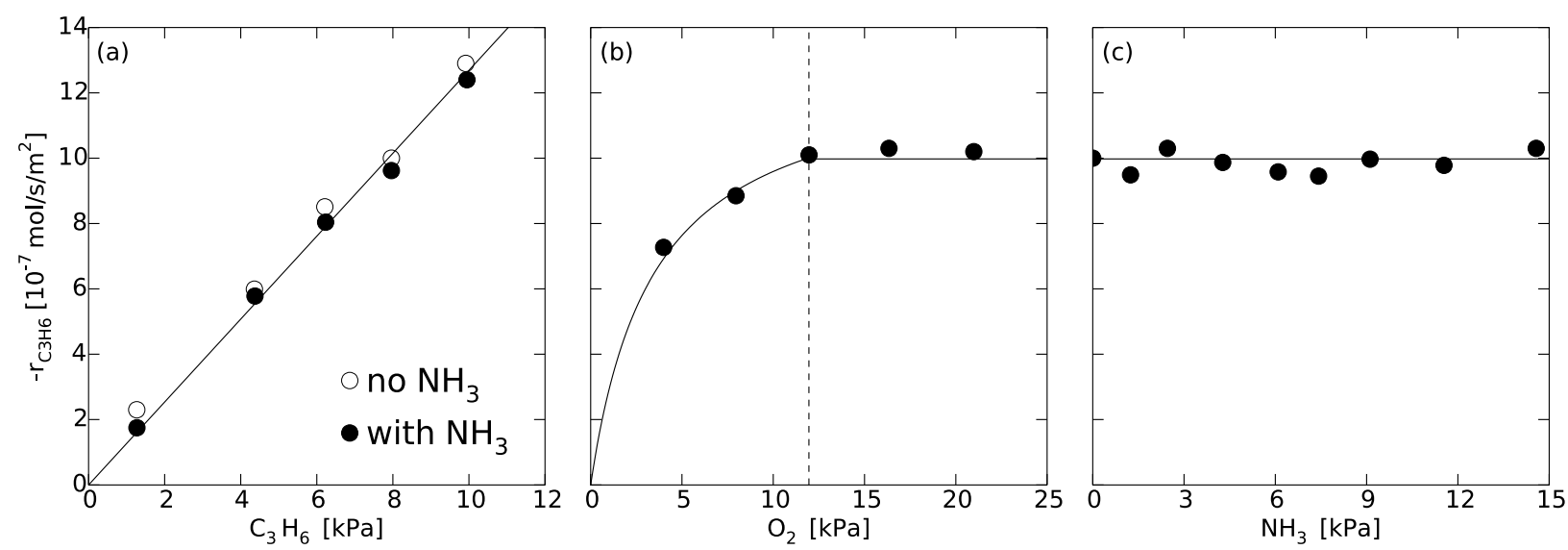

Fig. 1. Dependence of the rate of propene consumption on reactant feed partial pressures for reaction at $673 \mathrm{~K}$. Total propene conversion $0.8 \% \pm 0.1 \%$. (a) Dependence on $\mathrm{P}_{\mathrm{C} 3 \mathrm{H} 6}$ for $\mathrm{P}_{\mathrm{O} 2}=16.3$ $\mathrm{kPa}$ and $\mathrm{P}_{\mathrm{NH} 3}=0 \mathrm{kPa}$ (open symbol) or $7.4 \mathrm{kPa}$ (filled symbol). (b) Dependence on $\mathrm{P}_{\mathrm{O} 2}$ for $\mathrm{P}_{\mathrm{C} 3 \mathrm{H} 6}=8.0 \mathrm{kPa}$ and $\mathrm{P}_{\mathrm{NH} 3}=7.4 \mathrm{kPa}$. Vertical dashed line indicates the oxygen pressure where $\mathrm{O}_{2} / \mathrm{C}_{3} \mathrm{H}_{6}=1.5$. (c) Dependence on $\mathrm{P}_{\mathrm{NH} 3}$ for $\mathrm{P}_{\mathrm{C} 3 \mathrm{H} 6}=8.0 \mathrm{kPa}$ and $\mathrm{P}_{\mathrm{O} 2}=16.3 \mathrm{kPa}$. Lines are to guide the eye.

The dependence of ammonia consumption rate on reactant partial pressures is displayed in Fig. 2. We observe a slightly negative order dependence on propene partial pressure, a zero order dependence on oxygen pressure (except at very low $\mathrm{O}_{2}$ pressures), and a positive fractional order dependence on ammonia partial pressure. It is also significant that the rate of ammonia consumption is about an order of magnitude higher than the rate of propene consumption for a 
fixed set of reaction conditions. Therefore, as can be seen from the left-hand ordinate of Fig. 3, the ammonia conversion is substantial and variable across the range of ammonia partial pressures under conditions where propene conversion is always less than 1\%. Fig. 3 also shows the variation of the outlet water partial pressure with the partial pressure of ammonia in the feed, calculated by assuming that the reactor is at steady state and therefore all hydrogen atoms removed from propene or ammonia to produce products leaves as water. Clearly, the water partial pressure also varies significantly with the feed conditions.
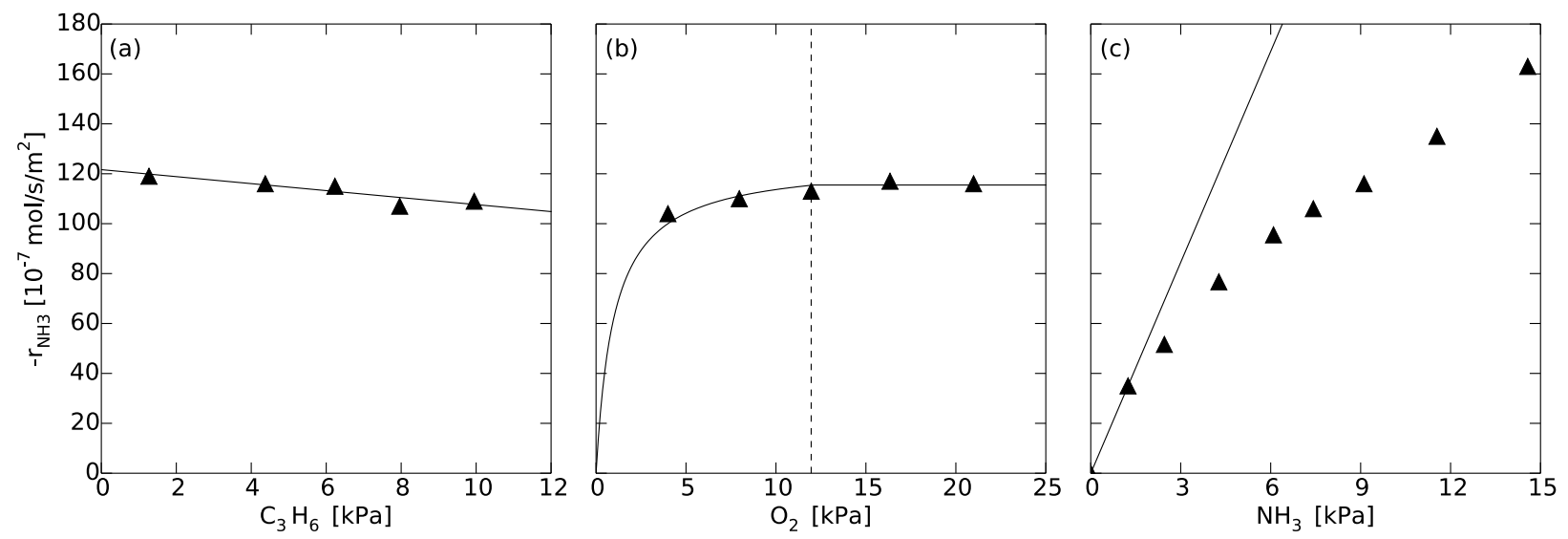

Fig. 2. Dependence of the rate of ammonia consumption on reactant feed partial pressures for reaction at $673 \mathrm{~K}$. Total propene conversion $0.8 \% \pm 0.1 \%$. (a) Dependence on $\mathrm{P}_{\mathrm{C} 3 \mathrm{H} 6}$ for $\mathrm{P}_{\mathrm{O} 2}=16.3$ $\mathrm{kPa}$ and $\mathrm{P}_{\mathrm{NH} 3}=7.4 \mathrm{kPa}$. (b) Dependence on $\mathrm{P}_{\mathrm{O} 2}$ for $\mathrm{P}_{\mathrm{C} 3 \mathrm{H} 6}=8.0 \mathrm{kPa}$ and $\mathrm{P}_{\mathrm{NH} 3}=7.4 \mathrm{kPa}$. Vertical dashed line indicates the oxygen pressure where $\mathrm{O}_{2} / \mathrm{C}_{3} \mathrm{H}_{6}=1.5$. (c) Dependence on $\mathrm{P}_{\mathrm{NH} 3}$ for $\mathrm{P}_{\mathrm{C} 3 \mathrm{H} 6}=8.0 \mathrm{kPa}$ and $\mathrm{P}_{\mathrm{O} 2}=16.3 \mathrm{kPa}$. Lines are to guide the eye. 


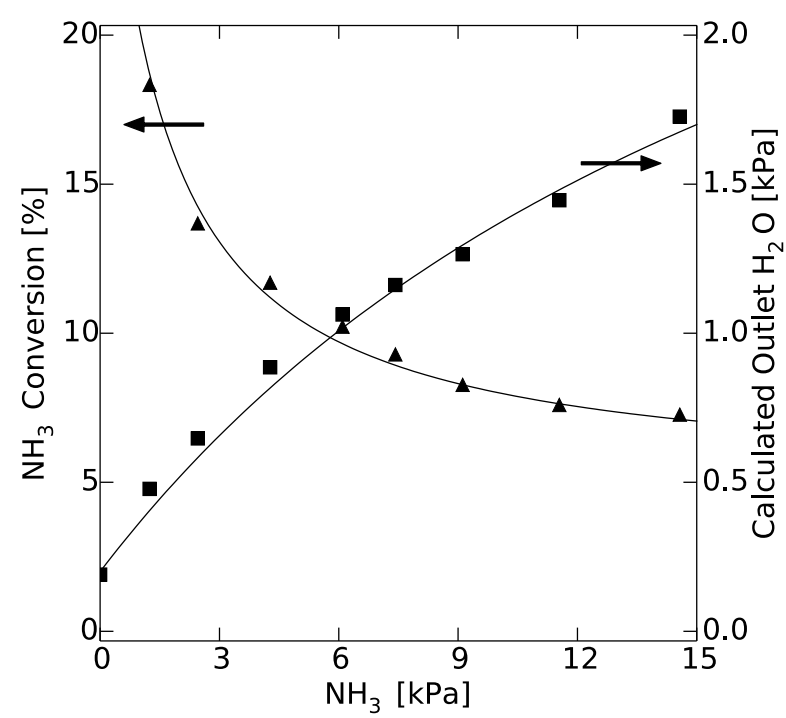

Fig. 3. The dependence of ammonia conversion (left axis, $\mathbf{\Delta}$ ) and calculated outlet water partial pressure (right axis, $\square$ ) on the inlet ammonia partial pressure at $673 \mathrm{~K} . \mathrm{P}_{\mathrm{C} 3 \mathrm{H} 6}=8.0 \mathrm{kPa}, \mathrm{P}_{\mathrm{O} 2}=$ $16.3 \mathrm{kPa}$ and total propene conversion $0.8 \% \pm 0.1 \%$. Lines are to guide the eye.

\subsubsection{Carbon and nitrogen selectivities}

Twelve carbon-containing products are observed during propene ammoxidation and their relative selectivities vary with reactor conditions. We have chosen to group these products into four general categories (see Table 1) based on similar identity and response to the addition of $\mathrm{NH}_{3}$. In Fig. 4 we display $\mathrm{C}$ selectivity versus $\mathrm{NH}_{3}$ pressure for only those species that have $<20 \% \mathrm{C}$ selectivity at all $\mathrm{NH}_{3}$ pressures in order to focus on these minor products and justify the category groupings we have made. Fig. 5 displays the response of the four product categories to $\mathrm{NH}_{3}$ pressure. The first category, designated as acrylonitrile or $\mathrm{ACN}$, consists of the sum of the primary ammoxidation product acrylonitrile and a small amount of propionitrile. As seen in Fig. 4, propionitrile has an approximately constant carbon selectivity of only $\sim 2.5 \%$ at all conditions with nonzero $\mathrm{NH}_{3}$. Because of its minor importance and its structural similarity to acrylonitrile, we group these products together. The second category, designated as acrolein or ACO, consists of the primary oxidation product, acrolein. The third category, designated as nitrogen-containing 
byproducts or NBP, is the carbon-scaled sum of the two major ammoxidation byproducts: hydrogen cyanide $(\mathrm{HCN})$ and acetonitrile. From the data in Fig. 4, we observe that the carbon selectivities to each of these two products have parallel responses to ammonia pressure. Additionally, they are always produced in the constant ratio of approximately 5 HCN: 2 acetonitrile, allowing us to group them together. The fourth category, designated as oxygencontaining byproducts or OBP, consists of the carbon-scaled sum of all carbon byproducts that do not contain nitrogen. More than $50 \%$ of this group is $\mathrm{CO}_{2}$, with the remainder consisting of $\mathrm{CO}$, acetaldehyde, and trace amounts of acetic acid, acetone, acrylic acid, and ethene. As seen in Fig. 4, the selectivity to each of these products decreases by over $50 \%$ upon ammonia addition and together only add up to $<10 \%$ selectivity when $\mathrm{NH}_{3} / \mathrm{C}_{3} \mathrm{H}_{6}=1$, therefore we group them together.

Product Category Name Abbreviation $\quad$ Included Compounds

\begin{tabular}{lll}
\hline Acrylonitrile & ACN & Acrylonitrile and Propionitrile \\
\hline Acrolein & ACO & Acrolein \\
\hline $\begin{array}{l}\text { Nitrogen-Containing } \\
\text { Byproducts }\end{array}$ & NBP & Hydrogen Cyanide and Acetonitrile \\
\hline $\begin{array}{l}\text { Oxygen-Containing } \\
\text { Byproducts }\end{array}$ & OBP & $\begin{array}{l}\text { Carbon Dioxide, Carbon Monoxide, } \\
\text { Acetaldehyde, Acetic Acid, Ethene, } \\
\text { Acrylic Acid and Acetone }\end{array}$ \\
\hline Nitrogen & N2 & Nitrogen and Nitrous Oxide
\end{tabular}

Table 1. Categorization of propene ammoxidation products. The right-hand column lists products in order of decreasing selectivity. 


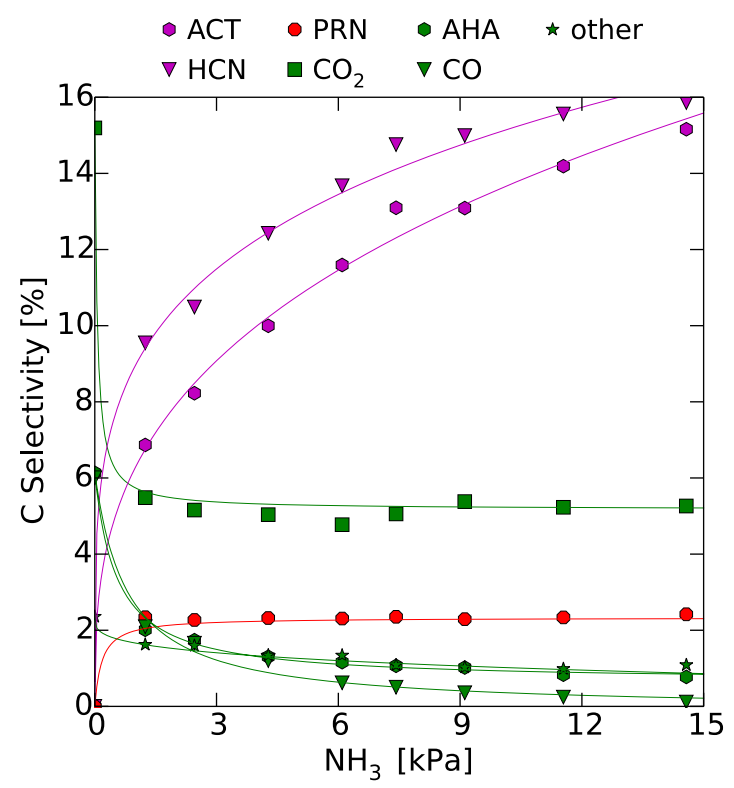

Fig. 4. Dependence of carbon-scaled byproduct selectivities on inlet ammonia partial pressure at $673 \mathrm{~K} . \mathrm{P}_{\mathrm{C} 3 \mathrm{H} 6}=8.0 \mathrm{kPa}, \mathrm{P}_{\mathrm{O} 2}=16.3 \mathrm{kPa}$, and total propene conversion $0.8 \% \pm 0.1 \%$. ACT $=$ acetonitrile, $\mathrm{PRN}=$ propionitrile, $\mathrm{AHA}=$ acetaldehyde, Other $=$ ethene + acetic acid + acetone. Lines are to guide the eye.

Fig. 5 (a) displays the carbon selectivities to these four product groups versus inlet ammonia partial pressure at low propene conversion. Even at the lowest experimentally attainable ammonia partial pressure, acrylonitrile $(\mathrm{ACN})$ becomes the primary product with a nearly constant selectivity of $\sim 60 \%$ across the entire range of non-zero ammonia pressures. The nitrogen-containing byproducts account for the majority of the remaining converted carbon. The selectivity to NBP increases monotonically with ammonia pressure, in contrast to the selectivity to $\mathrm{ACN}$ which plateaus at low ammonia partial pressures and then decreases slightly at very high ammonia partial pressures. Fig. 5 (a) shows that only $\sim 10 \%$ of the converted propene ends up in species that do not contain nitrogen, with the majority going to $\mathrm{CO}_{2}$ when at least stoichiometric ammonia is present in the feed. When no ammonia is present, the observed selectivity to the oxidation product acrolein is $\sim 70 \%$, however, as soon as ammonia is introduced, very little acrolein is observed in the reaction products, consistent with previous reports [27, 28]. 

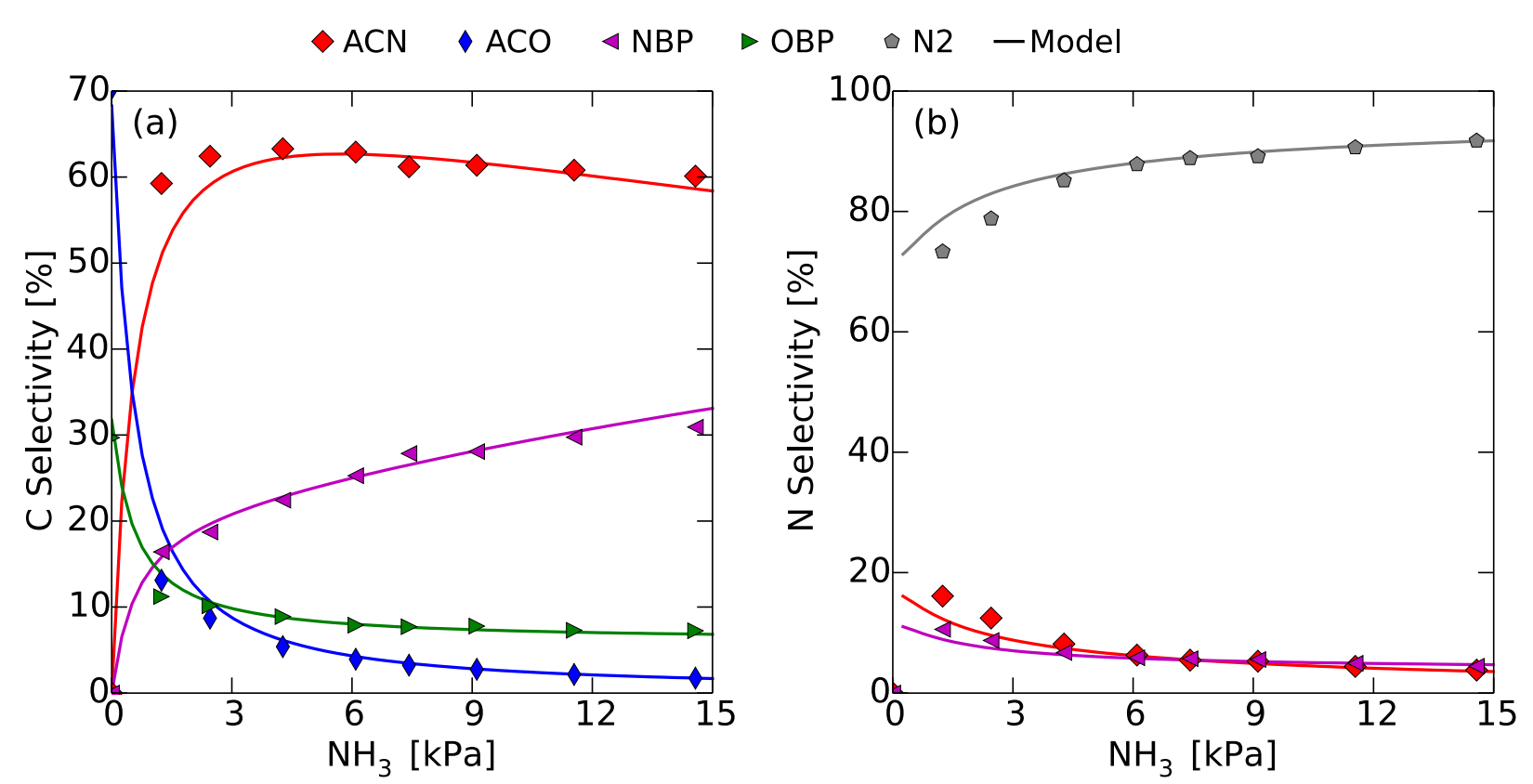

Fig. 5. Dependencies of (a) carbon-scaled product selectivities and (b) nitrogen-scaled product selectivities on inlet ammonia partial pressure at $673 \mathrm{~K} . \mathrm{P}_{\mathrm{C} 3 \mathrm{H} 6}=8.0 \mathrm{kPa}, \mathrm{P}_{\mathrm{O} 2}=16.3 \mathrm{kPa}$, and total propene conversion $0.8 \% \pm 0.1 \%$. Symbols are data points; lines are calculated from the reaction network model.

Fig. 6 (a) displays the carbon selectivities to the four product groups versus inlet oxygen partial pressure. Oxygen partial pressure does not have as pronounced an effect on the carbon selectivities as does the ammonia partial pressure, though we do observe a decrease in the ACN and an increase in NBP selectivities with increasing oxygen partial pressure. A plot of the natural $\log$ of the NBP rate versus the natural $\log$ of the oxygen partial pressure has a slope of 0.4 , indicating the existence of a reaction between a hydrocarbon intermediate and one $\mathrm{O}$ atom from $\mathrm{O}_{2}$ to form the nitrogen-containing byproducts. A similar effect was observed for propene oxidation over bismuth molybdate, where high pressures of oxygen resulted in a decreased selectivity to acrolein and an increased selectivity to the combustion products [26]. It should also be noted that the propene partial pressure had no observable effect on the product distribution. 

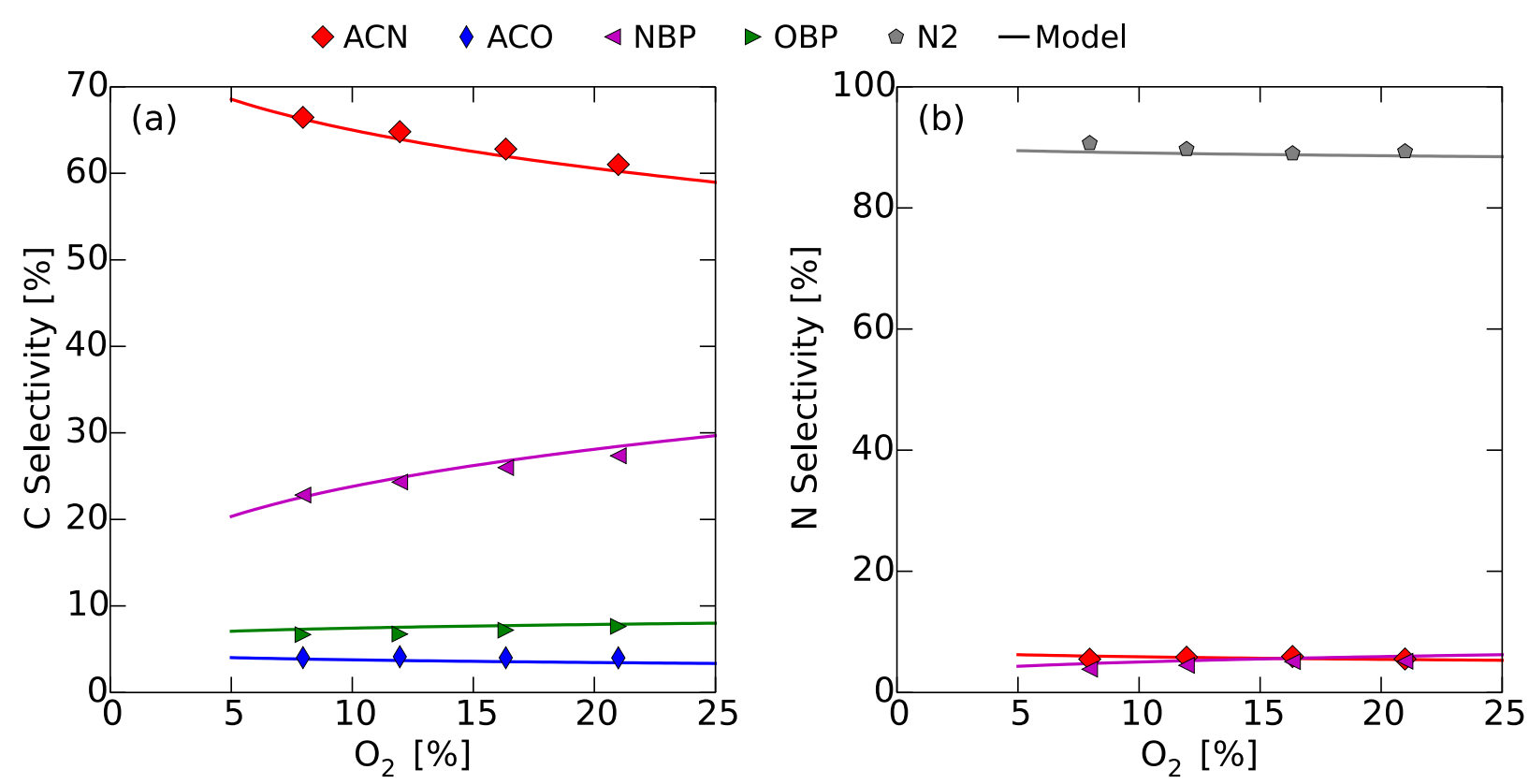

Fig. 6. Dependence of (a) carbon-scaled product selectivities and (b) nitrogen-scaled product selectivities on inlet oxygen partial pressure at $673 \mathrm{~K} . \mathrm{P}_{\mathrm{C} 3 \mathrm{H} 6}=8.0 \mathrm{kPa}, \mathrm{P}_{\mathrm{NH} 3}=7.4 \mathrm{kPa}$, and total propene conversion $0.8 \% \pm 0.1 \%$. Symbols are data points; lines are calculated from the reaction network model.

We also group the nitrogen-containing products into three categories. Again, acrylonitrile $(\mathrm{ACN})$ is the sum of acrylonitrile and very small amounts of propionitrile. The nitrogencontaining byproducts (NBP) again consist of hydrogen cyanide and acetonitrile, without scaling in this case since both compounds contain one nitrogen atom. The final category, nitrogen (N2), consists of molecular nitrogen and a small amount of nitrous oxide (<3\% N-selectivity). Since both species contain two nitrogen atoms, their sum is doubled to calculate the selectivity to the $\mathrm{N} 2$ product group.

Fig. 5 (b) displays the nitrogen selectivities to the three nitrogen product groups as a function of ammonia partial pressure. The primary product, with greater than $70 \% \mathrm{~N}$-scaled selectivity at all conditions, is molecular nitrogen formed by parasitic ammonia oxidation $\left(2 \mathrm{NH}_{3}\right.$ $+1.5 \mathrm{O}_{2} \rightarrow \mathrm{N}_{2}+3 \mathrm{H}_{2} \mathrm{O}$ ). The formation of the products containing $-\mathrm{CN}$ bonds (both $\mathrm{ACN}$ and NBP) accounts for less than $20 \%$ of the converted ammonia at stoichiometric conditions 
$\left(1 \mathrm{NH}_{3}: 1 \mathrm{C}_{3} \mathrm{H}_{6}\right)$ and $<1 \%$ propene conversion. The presence of excess ammonia results in combustion of ammonia to nitrogen, rather than increasing the formation of the desired $-\mathrm{CN}$ products. There is little effect of oxygen partial pressure on the nitrogen selectivities, as observed in Fig. 6 (b).

\subsubsection{Effects of water}

As observed in Fig. 3 (right ordinate), propene ammoxidation produces a substantial amount of water, even at low propene conversion. To explore the influence of water vapor on the reaction rates and selectivities, water vapor was added to the reactor feed. From Fig. 7, it is clear that the addition of water suppresses the rate of ammonia consumption significantly, while having a negligible effect on the rate of propene consumption. When $4.4 \mathrm{kPa}$ of water is added to the feed, the rate of ammonia consumption is decreased by almost an order of magnitude relative to the case with no additional water. This effect is attributed to suppression of the rate of ammonia oxidation to nitrogen, since the selectivity to this product is $\sim 90 \%$ at these conditions without the addition of water. We also note that by feeding $10.5 \mathrm{kPa} \mathrm{H}_{2} \mathrm{O}$, we were able to completely suppress the formation of $\mathrm{N}_{2}$. Fig. 8 displays the carbon (a) and nitrogen (b) selectivities as a function of the partial pressure of water in the feed. For the carbon-containing products, we observe a significant increase in the selectivity to acrolein, from $6 \%$ to $15 \%$. There is a commensurate decrease in the selectivities to both $\mathrm{ACN}$ and NBP, though the selectivity to ACN remains $\sim 60 \%$. For the nitrogen-containing products, we observe a substantial decrease in the N2 selectivity, much below that observed when only changing ammonia pressure. 


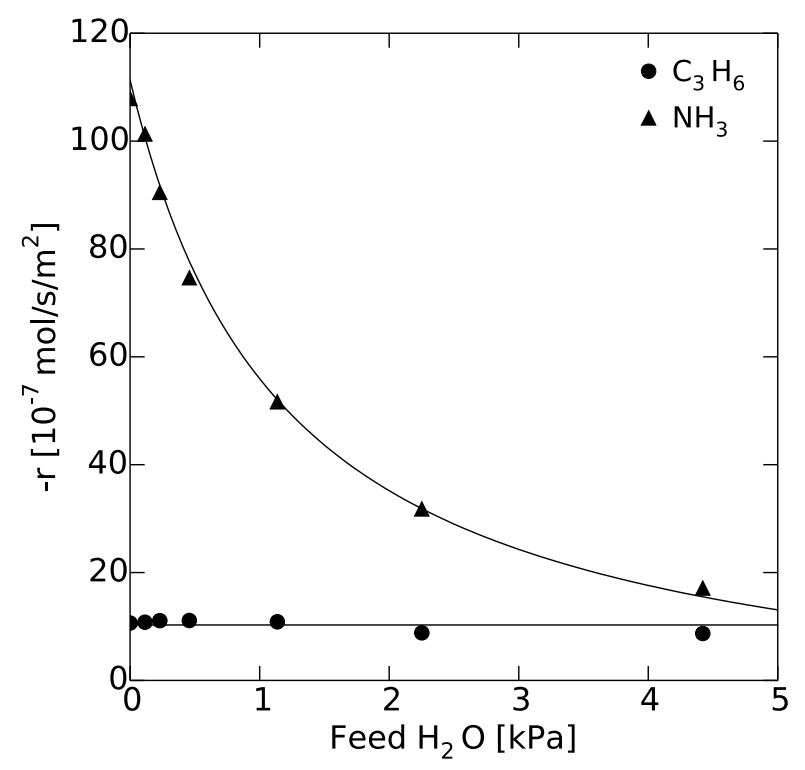

Fig. 7. Dependence of propene and ammonia consumption rates on feed water partial pressure. $673 \mathrm{~K}, \mathrm{P}_{\mathrm{C} 3 \mathrm{H} 6}=8.2 \mathrm{kPa}, \mathrm{P}_{\mathrm{NH} 3}=8.2 \mathrm{kPa}$, and $\mathrm{P}_{\mathrm{O} 2}=16.4 \mathrm{kPa}$. Total propene conversion $0.7 \% \pm 0.1 \%$. Lines are to guide the eye.

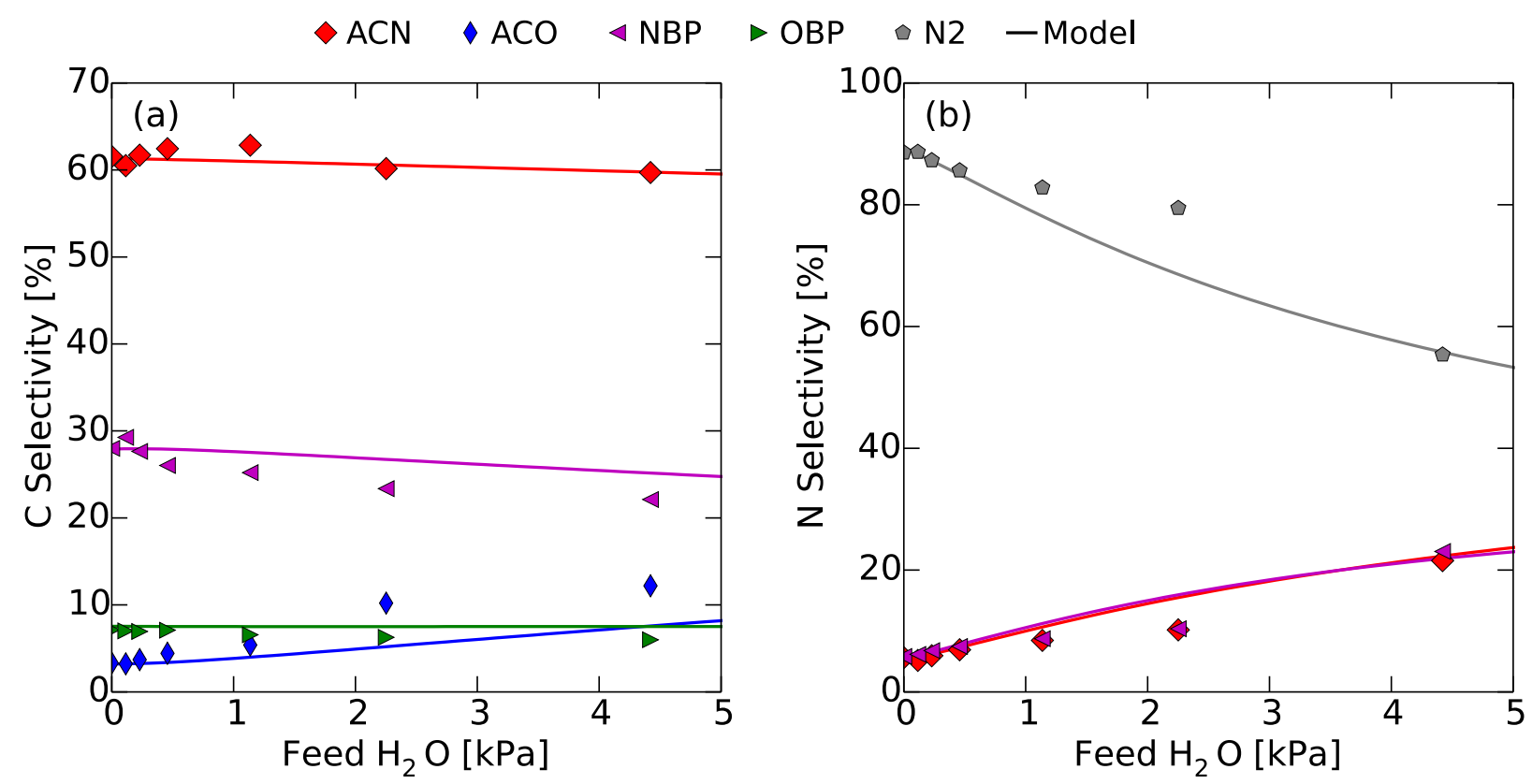

Fig. 8. Dependence of (a) carbon-scaled product selectivities and (b) nitrogen-scaled product selectivities on feed water partial pressure. $673 \mathrm{~K}, \mathrm{P}_{\mathrm{C} 3 \mathrm{H} 6}=8.2 \mathrm{kPa}, \mathrm{P}_{\mathrm{NH} 3}=8.2 \mathrm{kPa}$, and $\mathrm{P}_{\mathrm{O} 2}=$ $16.4 \mathrm{kPa}$. Total propene conversion $0.7 \% \pm 0.1 \%$. Symbols are data points; lines are calculated from the reaction network model.

A comparison of the effects of water on the steady-state rates of propene consumption for propene oxidation and ammoxidation are reported in Table 2. We note that, for propene 
oxidation over a fresh catalyst (base case used for normalization), the propene consumption rate is not affected by the presence of water (lines 1 and 2). However, if the catalyst is first pretreated with $\mathrm{NH}_{3}$ and $\mathrm{O}_{2}$, the propene consumption rate for propene oxidation increases by $\sim 1.6 \mathrm{x}$ relative to that for a fresh catalyst (line 3). However, if the $\mathrm{NH}_{3}$-treated catalyst is subsequently exposed to a high partial pressure of water plus $\mathrm{O}_{2}$, the rate of propene consumption returns to its base case value (line 4). Regardless of the catalyst pretreatment, the selectivity to ACO during propene oxidation is always $\sim 70 \%$. Exposure of a fresh catalyst to ammoxidation conditions causes the propene consumption rate to slowly increase over a period of $\sim 8 \mathrm{~h}$ until it reaches a rate that is $1.6 x$ that of propene oxidation on a fresh catalyst (line 5). Upon cessation of the $\mathrm{NH}_{3}$ flow, the rate of propene consumption at low conversion remained constant at this higher value for a period of at least $24 \mathrm{~h}$. However, treating the catalyst with a high partial pressure of water removes this rate enhancement (line 6). In both cases, the selectivity to $\mathrm{ACN}$ is $\sim 60 \%$. These results suggest that treatment of $\mathrm{Bi}_{2} \mathrm{Mo}_{3} \mathrm{O}_{12}$ with $\mathrm{NH}_{3}$ causes a change in the surface composition or the number of active sites exposed, leading to a $\sim 1.6 \mathrm{x}$ increase in propene activation activity. However, this activity increase can be undone by exposure to high concentrations of water vapor, and is therefore likely only relevant at low propene conversions.

\begin{tabular}{ccc} 
Reactor Feed & Catalyst Pretreatment & Normalized S.S. $-\mathrm{r}_{\mathrm{C} 3 \mathrm{H} 6}$ \\
\hline $\mathrm{C}_{3} \mathrm{H}_{6}+\mathrm{O}_{2}$ & (none) & 1.00 \\
\hline $\mathrm{C}_{3} \mathrm{H}_{6}+\mathrm{O}_{2}+\mathrm{H}_{2} \mathrm{O}$ & (none) & 1.02 \\
\hline $\mathrm{C}_{3} \mathrm{H}_{6}+\mathrm{O}_{2}$ & $\mathrm{NH}_{3}$ & 1.59 \\
\hline $\mathrm{C}_{3} \mathrm{H}_{6}+\mathrm{O}_{2}+\mathrm{H}_{2} \mathrm{O}$ & $(1) \mathrm{NH}_{3} ;(2) \mathrm{H}_{2} \mathrm{O}$ & 0.97 \\
\hline $\mathrm{C}_{3} \mathrm{H}_{6}+\mathrm{O}_{2}+\mathrm{NH}_{3}$ & $\mathrm{NH}_{3}$ & 1.63 \\
\hline $\mathrm{C}_{3} \mathrm{H}_{6}+\mathrm{O}_{2}+\mathrm{NH}_{3}+\mathrm{H}_{2} \mathrm{O}$ & $(1) \mathrm{NH}_{3} ;(2) \mathrm{H}_{2} \mathrm{O}$ & 0.92
\end{tabular}

Table 2. Normalized steady-state rate of propene consumption as a function of the reactor feed and catalyst pretreatment. Reactor feed as indicated in the table, with $\mathrm{P}_{\mathrm{C} 3 \mathrm{H} 6}=8.0 \mathrm{kPa}, \mathrm{P}_{\mathrm{NH} 3}=8.0$ $\mathrm{kPa}, \mathrm{P}_{\mathrm{O} 2}=16.0 \mathrm{kPa}$, and $\mathrm{P}_{\mathrm{H} 2 \mathrm{O}}=10.5 \mathrm{kPa}$. A (none) pretreatment indicates freshly calcined catalyst. $\mathrm{NH}_{3}$ pretreatment involves exposure to $\mathrm{P}_{\mathrm{NH} 3}=8.0 \mathrm{kPa}$ and $\mathrm{P}_{\mathrm{O} 2}=16.0 \mathrm{kPa}$ for $24 \mathrm{~h}$; a $\mathrm{H}_{2} \mathrm{O}$ pre-treatment is exposure to $\mathrm{P}_{\mathrm{H} 2 \mathrm{O}}=10.5 \mathrm{kPa}$ and $\mathrm{P}_{\mathrm{O} 2}=16.0 \mathrm{kPa}$ for $12 \mathrm{~h}$. The reported 
normalized rate of propene consumption is measured after the rate has reached a steady-state level for the specified reactor feed.

\subsection{Secondary reactions}

\subsubsection{Selectivity versus conversion}

To distinguish whether the products of propene ammoxidation are formed via primary reaction or secondary reaction of the primary products, we examined the manner in which the carbon-scaled product selectivities changed with propene conversion. Fig. 9 shows that, for very low propene conversion $(<0.7 \%)$, there is a relatively higher selectivity to acrolein and lower selectivity to acrylonitrile than observed at higher conversions. It is notable that the selectivities to the nitrogen- and oxygen-containing byproducts remain essentially constant with conversion. The change in selectivity with conversion becomes increasingly important as the ammonia partial pressure is decreased, though no matter what ammonia pressure is fed, changes in selectivity at less than $0.7 \%$ conversion are always observed. These results suggest that acrolein does undergo secondary reaction to form acrylonitrile, although, in agreement with literature $[27,28]$, this does not appear to be the major route to acrylonitrile, since, even at $0.2 \%$ conversion, the ACN selectivity is still greater than $55 \%$. 

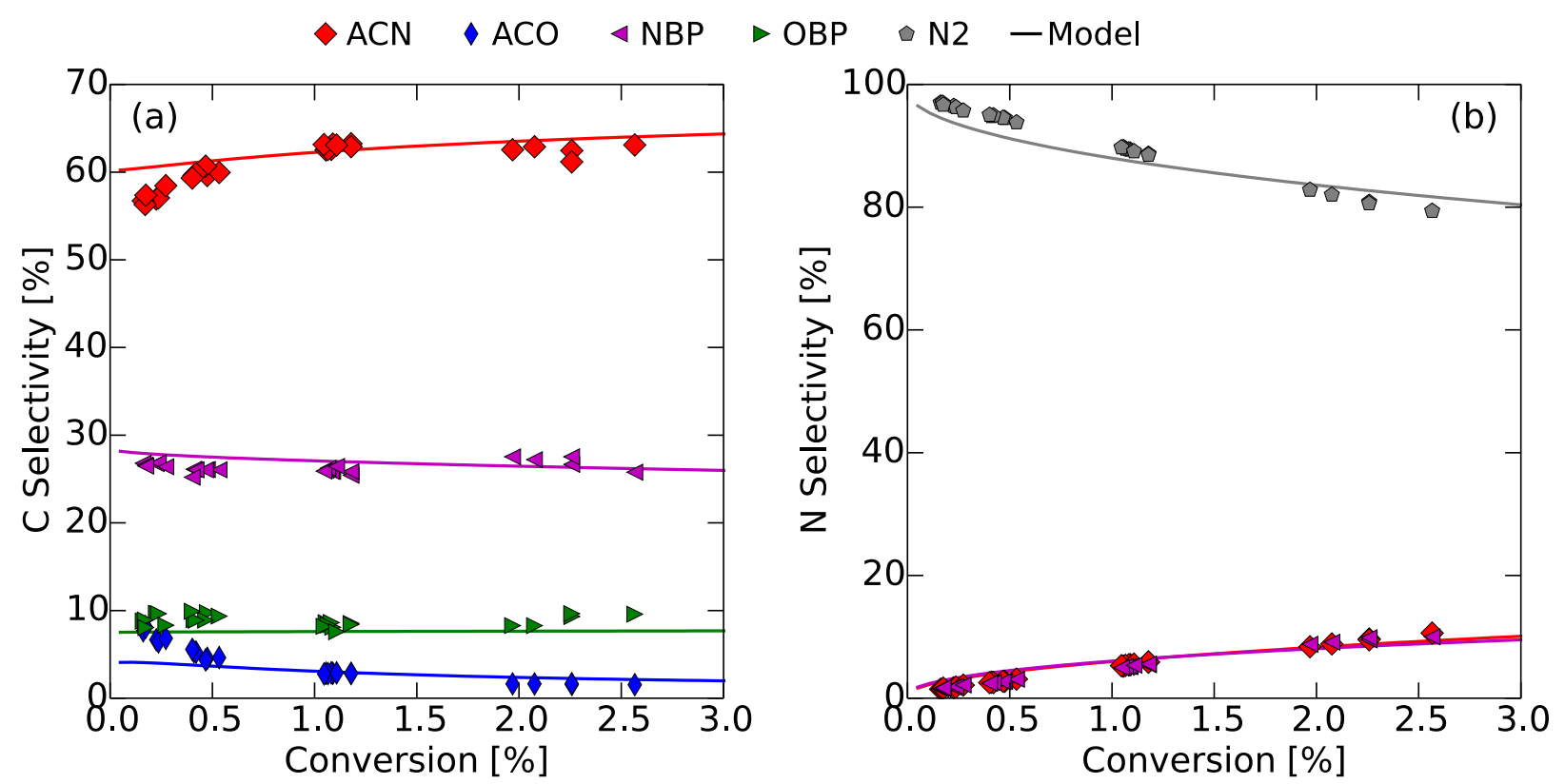

Fig. 9. Dependence of (a) carbon-scaled product selectivities and (b) nitrogen-scaled product selectivities, both versus propene conversion at $673 \mathrm{~K}, \mathrm{P}_{\mathrm{C} 3 \mathrm{H} 6}=8.0 \mathrm{kPa}, \mathrm{P}_{\mathrm{NH} 3}=8.0 \mathrm{kPa}$, and $\mathrm{P}_{\mathrm{O} 2}$ $=16.0 \mathrm{kPa}$. Symbols are data points; lines are calculated from the reaction network model.

The data in Fig. 9 also show that both the nitrogen- and oxygen-containing byproducts are formed via primary routes, and not by secondary (amm)oxidation of the primary 3-carbon products, since neither selectivity goes to $0 \%$ at $0 \%$ conversion. This finding is consistent with previous work, which has shown that for propene oxidation, oxygen-containing byproducts are not formed by combustion of acrolein [30]. We also observe a decrease in the nitrogen selectivity from almost $100 \%$ to $80 \%$ with increased conversion, explainable by water inhibition of ammonia oxidation with the increased water formation at higher conversion.

\subsubsection{Secondary Reactions of Primary Products}

To further explore the role of secondary reactions, acrolein was fed to the reactor at 673 $\mathrm{K}$ together with ammonia and oxygen. Line 1 of Table 3 shows that acrolein converts almost completely to nitrogen-containing products when fed with ammonia, in agreement with prior studies [27]. At this high conversion of acrolein, we observe $~ 90 \%$ selectivity to acrylonitrile, 
with the remainder of the carbon going to the nitrogen- or oxygen-containing byproducts. By contrast, when either acrylonitrile or acetonitrile (lines 2 and 3 of Table 3, respectively) is fed to the reactor with ammonia and oxygen, the conversion is less than $1 \%$, indicating that both products are relatively stable to secondary reaction. Similar results were obtained in the presence of propene in the feed stream. The much higher ratio of ACN to NBP when acrolein is the reactant compared to when propene is the reactant is another indication that most of the nitrogencontaining products are not formed via acrolein. In fact, the low selectivity to the nitrogencontaining byproducts from acrolein, as well as the negligible conversion of acrylonitrile, allows us to neglect all secondary pathways to the byproducts to a first approximation.

\section{Feed $\quad$ Conv. (\%) Sel. ACN (\%) Sel. ACO (\%) Sel. NBP (\%)}

\begin{tabular}{ccccc}
\hline \hline Acrolein $+\mathrm{O}_{2}+\mathrm{NH}_{3}$ & 80 & 90 & -- & 7 \\
\hline Acrylonitrile $+\mathrm{O}_{2}+\mathrm{NH}_{3}$ & $<1$ & -- & -- & 60 \\
\hline Acetonitrile $+\mathrm{O}_{2}+\mathrm{NH}_{3}$ & $<1$ & -- & -- & 50 \\
\hline Allylamine $+\mathrm{O}_{2}$ & $\sim 50$ & 53 & 23 & 18 \\
\hline Allylamine $+\mathrm{O}_{2}+\mathrm{NH}_{3}$ & $\sim 50$ & 56 & 9 & 29 \\
\hline Allylamine $+\mathrm{O}_{2}+\mathrm{H}_{2} \mathrm{O}$ & $\sim 50$ & 56 & 28 & 9 \\
\hline 1,2-diaminopropane $+\mathrm{O}_{2}$ & 0 & & & \\
\hline
\end{tabular}

Table 3. Conversion of acrolein, acrylonitrile, allylamine, and 1,2-diaminopropane over $\mathrm{Bi}_{2} \mathrm{Mo}_{3} \mathrm{O}_{12}$ at $673 \mathrm{~K}$ with $\mathrm{P}_{\text {hydrocarbon }}=0.2 \mathrm{kPa}$ and $\mathrm{P}_{\mathrm{O} 2}=16.3 \mathrm{kPa}$. Where indicated in table, $\mathrm{P}_{\mathrm{NH} 3}$ $=8.2$ or $\mathrm{P}_{\mathrm{H} 2 \mathrm{O}}=2 \mathrm{kPa}$. Carbon-scaled conversion (\%) and selectivities (\%) to ACN, ACO, and $\mathrm{NBP}$, with remaining carbon conversion to OBP.

The reactivity of allylamine was also investigated. We note that pure allylamine could not be detected by the FID, presumably because of the tendency of the compound to adsorb strongly on the column of the gas chromatograph and the lines connecting it to the detector, resulting in a broad peak that could not integrated be reliably. However, by measuring the reaction products and knowing the inlet concentration of allylamine, the conversion of allyamine was estimated to 
be $\sim 50 \%$ at the reaction conditions used for the other experiments listed in Table 3. Allylamine was reacted in the presence of oxygen (line 4), oxygen and ammonia (line 5), and oxygen and water (line 6). In all cases, the primary product was acrylonitrile, though products in all the other carbon product categories were also observed. Note that propionitrile had a carbon-scaled selectivity of $<3 \%$ in all cases with allylamine as the reactant, so it is again lumped with acrylonitrile in the ACN product group. When ammonia was co-fed, the selectivity to the nitrogen-containing byproducts increased substantially, and when water was co-fed, the selectivity to acrolein increased substantially. The role of allylamine as a possible intermediate in propene ammoxidation will be discussed in Section 4.2. Finally, 1,2-diaminopropane was also fed over the catalyst and observed to have no observable reactivity to any product.

\subsubsection{Kinetics of acrolein consumption}

The data in Sections 3.2.1 and 3.2.2 lead to the conclusion that the reaction of acrolein and ammonia to form acrylonitrile is the only significant secondary process. In order to understand this reaction further, we investigated the kinetics of this reaction at $603 \mathrm{~K}$. A lower temperature was required in order to attain acrolein conversions below $\sim 5 \%$. Fig. 10 illustrates that, at low partial pressures, the rate of acrylonitrile formation is first order in acrolein partial pressure, zeroth order in oxygen partial pressure, and first order in ammonia partial pressure.
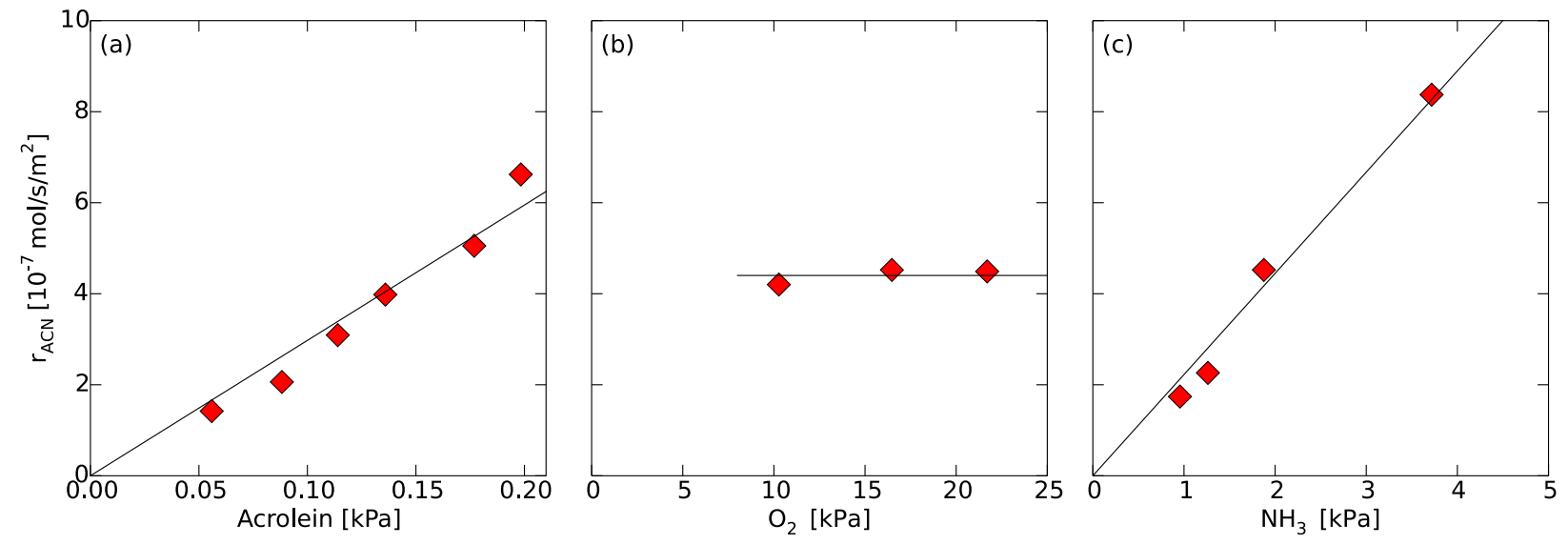
Fig. 10. Dependence of the rate of acrylonitrile formation on reactant feed partial pressures for the reaction of acrolein at $603 \mathrm{~K}$. Total acrolein conversion $5 \% \pm 2 \%$. (a) Dependence on $\mathrm{P}_{\text {acrolein }}$ with $\mathrm{P}_{\mathrm{O} 2}=16.5 \mathrm{kPa}$ and $\mathrm{P}_{\mathrm{NH} 3}=1.9 \mathrm{kPa}$. (b) Dependence on $\mathrm{P}_{\mathrm{O} 2}$ with $\mathrm{P}_{\text {acrolein }}=0.14 \mathrm{kPa}$ and $\mathrm{P}_{\mathrm{NH} 3}$ $=1.9 \mathrm{kPa}$. (c) Dependence of $\mathrm{P}_{\mathrm{NH} 3}$ with $\mathrm{P}_{\text {acrolein }}=0.14 \mathrm{kPa}$ and $\mathrm{P}_{\mathrm{O} 2}=16.5 \mathrm{kPa}$. Lines are to guide the eye.

\subsection{Effects of Temperature}

An Arrhenius plot of the apparent rate coefficient ( $k_{R L S}$ defined in Eqn. 3) for the rate of propene consumption during propene ammoxidation $(603-733 \mathrm{~K})$ is shown in Fig. S2. The data can be fit to a single line, the slope of which gives an activation energy of $22.4 \mathrm{kcal} / \mathrm{mol}$. This value agrees very well with the activation energy calculated the same way for propene oxidation, $21.7 \mathrm{kcal} / \mathrm{mol}$, for a slightly lower temperature range $(573-713 \mathrm{~K})$ (see also Fig. S2).

Fig. 11 shows the carbon (a) and nitrogen (b) selectivities for each of the product groups across the same temperature range for conversions of $0.2-0.5 \%, 1.4-1.9 \%$, and $2.7-3.4 \%$. Two regimes are observed: one below $\sim 673 \mathrm{~K}$ in which the selectivity to acrylonitrile decreases and the selectivity to the nitrogen-containing byproducts increases as the temperature decreases, and a second regime above $\sim 673 \mathrm{~K}$ in which the selectivity to acrolein increases and the selectivity to the nitrogen-containing byproducts decreases as the temperature increases. It is noted that the selectivity to the oxygen-containing byproducts is essentially constant at $\sim 10 \%$ for all conversions and temperatures. 

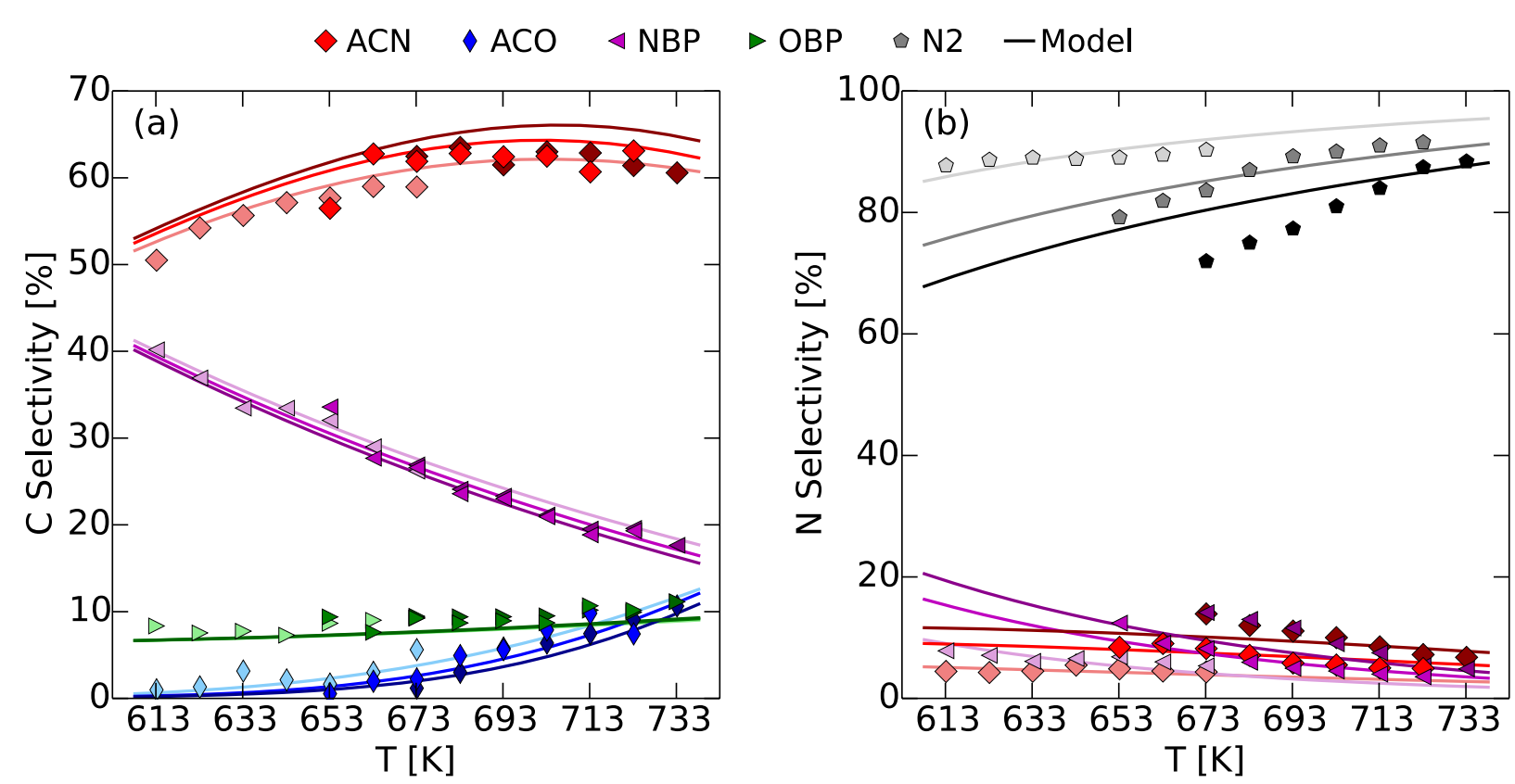

Fig. 11. Dependence of (a) carbon-scaled product selectivities and (b) nitrogen-scaled product selectivities on temperature. $\mathrm{P}_{\mathrm{C} 3 \mathrm{H} 6}=8.0 \mathrm{kPa}, \mathrm{P}_{\mathrm{NH} 3}=8.0 \mathrm{kPa}$, and $\mathrm{P}_{\mathrm{O} 2}=16.0 \mathrm{kPa}$. Symbols are data points; lines are calculated from the reaction network model. Light color $=$ low $\mathrm{C}_{3} \mathrm{H}_{6}$ conversion (data $0.2-0.5 \%$, model $0.4 \%$ ), medium color $=$ medium $\mathrm{C}_{3} \mathrm{H}_{6}$ conversion (data 1.4$1.9 \%$, model $1.6 \%)$, dark color $=$ high conversion $($ data $2.7-3.4 \%$, model $3.0 \%)$.

As noted above, we report activation energies for propene oxidation and ammoxidation on the basis of the rate of propene consumption $\left(\mathrm{k}_{\mathrm{RLS}}=\ln \left(-\mathrm{r}_{\mathrm{C} 3 \mathrm{H} 6} / \mathrm{P}_{\mathrm{C} 3 \mathrm{H} 6}\right)\right.$ vs. $\left.1 / \mathrm{T}\right)$. This approach differs from that used in literature, where authors report activation energies based on the rate of primary product (acrolein or acrylonitrile) formation $\left(\ln \left(\mathrm{r}_{\mathrm{ACO}} / \mathrm{P}_{\mathrm{C} 3 \mathrm{H} 6}\right)\right.$ or $\ln \left(\mathrm{r}_{\mathrm{ACN}} / \mathrm{P}_{\mathrm{C} 3 \mathrm{H} 6}\right)$ vs. 1/T). We consider our approach to be more physically meaningful, since the $\mathrm{C}$ selectivities change in a complex way with both temperature (Fig. 11) and partial pressures (Figs. 5 and 6), but the rate of propene consumption is strictly first order in propene partial pressures and zero order in both ammonia and oxygen $\left(\mathrm{O}_{2} / \mathrm{C}_{3} \mathrm{H}_{6}>1.5\right)$ partial pressures, resulting in a truly linear Arrhenius plot (Fig. S2). Additionally, since the products are thought to proceed via a common, initial, ratelimiting step (see Section 4.2 for more discussion) [11,12,29], the apparent activation energy determined from an Arrhenius plot based on propene consumption is the physically significant 
quantity describing propene activation, whereas the physical significance of an apparent activation energy determined from an Arrhenius plot based on product formation is not obvious. Nevertheless, to compare our results with those of previous researchers, we calculated the apparent activation energy for acrylonitrile formation for temperatures from 673 to $733 \mathrm{~K}$, over which the Arrhenius plot is approximately linear. The resulting values are $19.4 \mathrm{kcal} / \mathrm{mol}$ for propene ammoxidation and $19.9 \mathrm{kcal} / \mathrm{mol}$ for propene oxidation, both of which agree very well with values by other researchers for similar catalysts (see Table 4). Though there is some variation in the exact values, there is general agreement that the activation energy for acrylonitrile formation is essentially identical to that for acrolein formation.

\begin{tabular}{cccc}
$\begin{array}{c}\text { Reference } \\
(\text { Catalyst })\end{array}$ & $\begin{array}{c}\text { Calculation } \\
\text { Method }\end{array}$ & Oxidation & Ammoxidation \\
\hline \hline This work & Propene & 21.7 & 22.4 \\
$\mathrm{Bi}_{2} \mathrm{Mo}_{3} \mathrm{O}_{12}$ & Consumption & $(573-713 \mathrm{~K})$ & $(603-733 \mathrm{~K})$ \\
\hline This work & Product & 19.9 & 19.4 \\
$\mathrm{Bi}_{2} \mathrm{Mo}_{3} \mathrm{O}_{12}$ & Formation* & $(573-713 \mathrm{~K})$ & $(673-733 \mathrm{~K})$ \\
\hline \hline
\end{tabular}

Grasselli et al. [27]

Product

19

(Bi-P-Mo-O/SiO

Formation*

(Near 698 K)

$\mathrm{Bi} / \mathrm{Mo}=1.63$ )

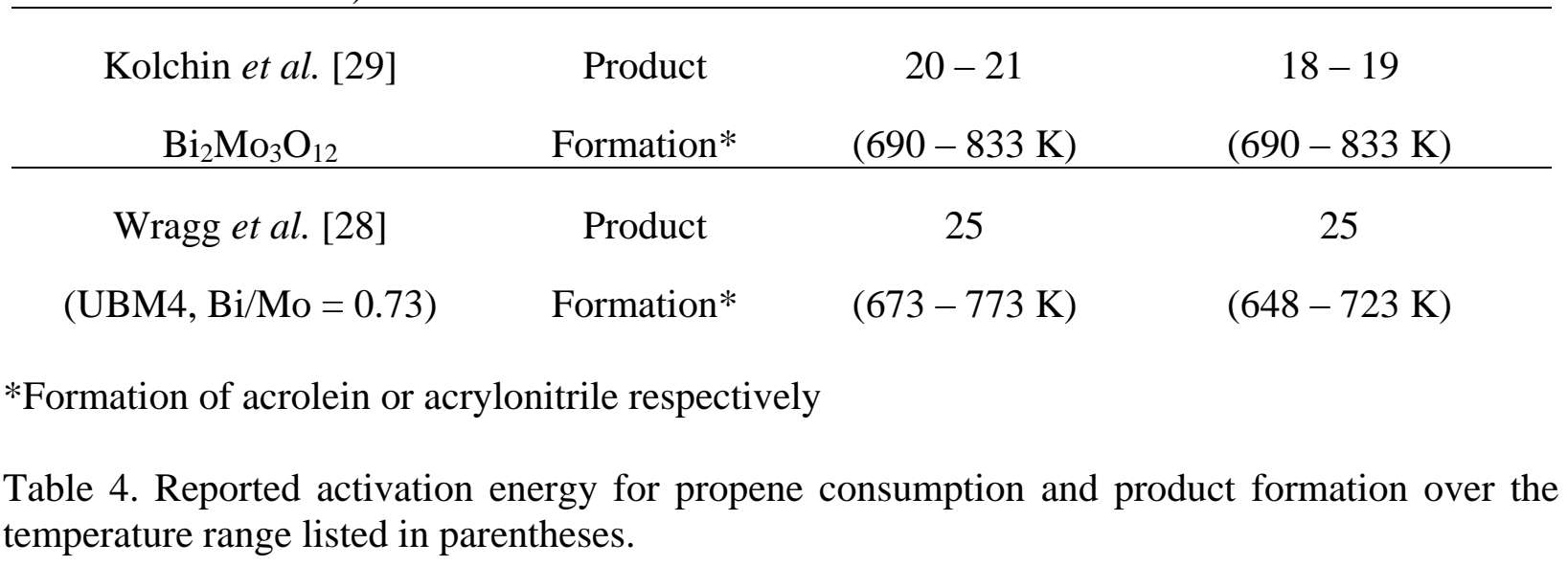




\section{Discussion}

Deductions drawn from the experimental results reported in the preceding section enable us to propose a new mechanism for the ammoxidation of propene over bismuth molybdate, which is illustrated in Scheme 1. Justifications for the steps included in this scheme are presented in Section 4.2, while Section 4.3 discusses the use of the proposed mechanism to describe the kinetics of propene ammoxidation. The results of this model are presented as the solid curves appearing in Figs. 5, 6, 8, 9, 11 and 12.

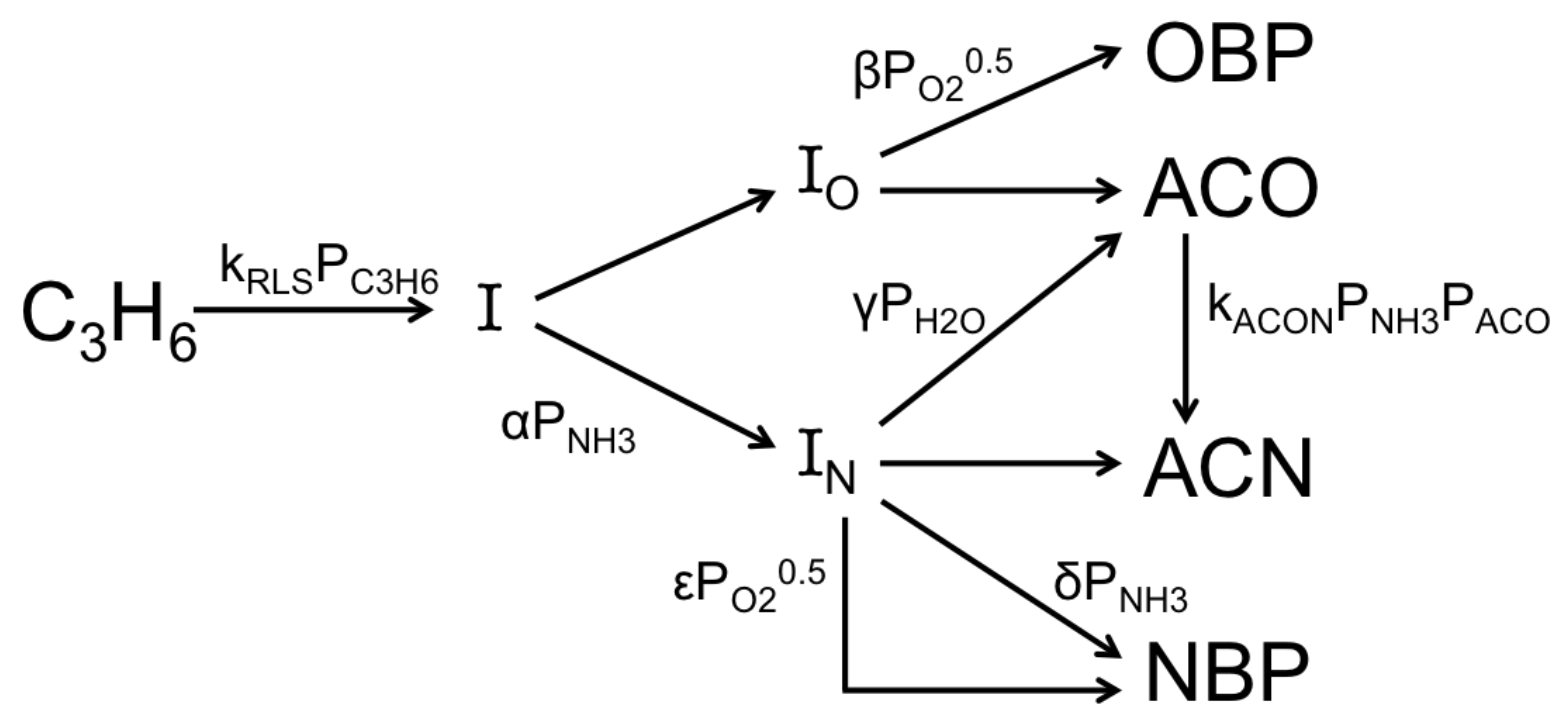

Scheme 1. Overall reaction scheme showing proposed routes to all major carbon-containing product groups.

\subsection{Relevant Nitrogen Species}

We propose that two $\mathrm{N}$-containing species are present on the surface of $\mathrm{Bi}_{2} \mathrm{Mo}_{3} \mathrm{O}_{12}: \mathrm{NH}_{3}$ adsorbed on $\mathrm{Bi}^{3+}$ cations that are responsible for $\mathrm{C}-\mathrm{N}$ bond formation and metastable $\mathrm{M}-\mathrm{NH}_{\mathrm{x}}(\mathrm{M}$ $=\mathrm{Mo}, \mathrm{Bi} ; \mathrm{x}=1,2)$ species that are involved in $\mathrm{N}_{2}$ formation, but are readily destroyed by reaction with water vapor. As discussed below, a very low surface concentration of $\mathrm{Mo}=\mathrm{NH}$ 
species may also be responsible for the $60 \%$ enhancement in the rate of propene consumption after the catalyst has been pretreated with $\mathrm{NH}_{3}$ and $\mathrm{O}_{2}$ (see Table 2), which disappears upon exposure of the catalyst to high concentrations of water vapor.

The primary reason for proposing two distinct N-containing surface species is the observed differences in the responses of the rates of propene ammoxidation and of ammonia oxidation to the co-feeding of water. The rate of acrylonitrile formation is essentially unchanged upon addition of a moderate partial pressure of water, demonstrating that the $\mathrm{N}$-containing species involved in $\mathrm{C}-\mathrm{N}$ bond formation are unaffected by water. However, ammonia oxidation to $\mathrm{N}_{2}$ is significantly suppressed by even a small partial pressure of water, achieved by either introducing water into the feed or by operating at higher propene conversion. We note that $\mathrm{N}_{2}$ formation can be completely suppressed by feeding a sufficiently high concentration of water, indicating that the $\mathrm{N}$-containing species involved in $\mathrm{N}_{2}$ formation is very sensitive to the presence of water.

DFT calculations of the interaction of $\mathrm{NH}_{3}$ with $(\mathrm{O}=\mathrm{Mo}=\mathrm{O})_{2} \mathrm{Bi}_{2} \mathrm{O}_{10} \mathrm{H}_{10}$, a cluster chosen to represent a part of the (010) surface of $\mathrm{Bi}_{2} \mathrm{Mo}_{3} \mathrm{O}_{12}$ (see Supporting Information for more details), show no evidence for $\mathrm{NH}_{3}$ interaction with $\mathrm{Mo}^{6+}$ ions. However, adsorption of $\mathrm{NH}_{3}$ on $\mathrm{Bi}^{3+}$ cations via a $\sigma$-donation of electron density from the lone pair on the $\mathrm{N}$ atom is favorable. This type of interaction is similar to that proposed by Matsuura to explain the observation of weakly adsorbed $\mathrm{NH}_{3}$ on the surface of $\mathrm{Bi}_{2} \mathrm{MoO}_{6}\left(\Delta \mathrm{H}_{\text {ads }}=-6.2 \mathrm{kcal} / \mathrm{mol}\right)$ [35]. Using our model cluster, we calculate $\Delta \mathrm{H}_{\mathrm{ads}, 673 \mathrm{~K}}=-12.7 \mathrm{kcal} / \mathrm{mol}$ and $\Delta \mathrm{G}_{\text {ads,673K }}=-7 \mathrm{kcal} / \mathrm{mol}$ for adsorption of $\mathrm{NH}_{3}$ on $\mathrm{Bi}^{3+}$. The corresponding equilibrium constant for $\mathrm{NH}_{3}$ adsorption at $673 \mathrm{~K}$ is $\mathrm{K}_{\mathrm{eq}} \sim 1.7$, and, assuming Langmuirian adsorption, the fraction of $\mathrm{Bi}^{3+}$ cations occupied by $\mathrm{NH}_{3}$ is $\sim 0.1$ at a representative $\mathrm{NH}_{3}$ pressure of $8 \mathrm{kPa}$. We note further that the calculated enthalpy of $\mathrm{NH}_{3}$ 
adsorption is unaffected by the presence or absence of a hydrocarbon intermediate on the neighboring Mo site.

The next question is whether water might displace adsorbed $\mathrm{NH}_{3}$, since $\mathrm{H}_{2} \mathrm{O}$ could also interact with $\mathrm{Bi}^{3+}$ cations via sigma donation from the lone pair of electrons on oxygen. Our calculations indicate that the free energy for the adsorption of water is $3 \mathrm{kcal} / \mathrm{mol}$ less favorable than that for $\mathrm{NH}_{3}$. Therefore, the addition of water, especially at a lower partial pressure than that of $\mathrm{NH}_{3}$, should not significantly impact the low surface coverage of adsorbed $\mathrm{NH}_{3}$. This insensitivity to water makes adsorbed $\mathrm{NH}_{3}$ an attractive candidate for the $\mathrm{N}$-containing species responsible for $\mathrm{C}-\mathrm{N}$ bond formation. The occupancy of $\mathrm{Bi}^{3+}$ sites by $\mathrm{NH}_{3}$ is expected to increase linearly with $\mathrm{NH}_{3}$ partial pressure, since the occupancy of these cations is predicted to be in the Henry's law regime. If, as discussed in Section 4.2, the formation of acrolein and acrylonitrile proceeds via a common intermediate that can react with adsorbed $\mathrm{NH}_{3}$ to produce a precursor to acrylonitrile or undergo additional hydrogen abstraction to produce acrolein, the ratio of acrylonitrile to acrolein should depend on the occupancy of $\mathrm{Bi}^{3+}$ cations by $\mathrm{NH}_{3}$ and should therefore increase linearly with $\mathrm{NH}_{3}$ partial pressure. The data points in Fig. 12 (a) indicate that this ratio is indeed nearly linear with $\mathrm{NH}_{3}$ partial pressure for a range of temperatures, consistent with our proposal that reaction with adsorbed $\mathrm{NH}_{3}$ is responsible for $\mathrm{C}-\mathrm{N}$ bond formation. It is for this reason that the rate of $I_{N}$ formation in Scheme 1 is shown to depend on the first power of the $\mathrm{NH}_{3}$ partial pressure. This relationship is used in the model of the reaction network (Scheme 1) in order to generate the best-fit lines appearing in Fig. 12a. 

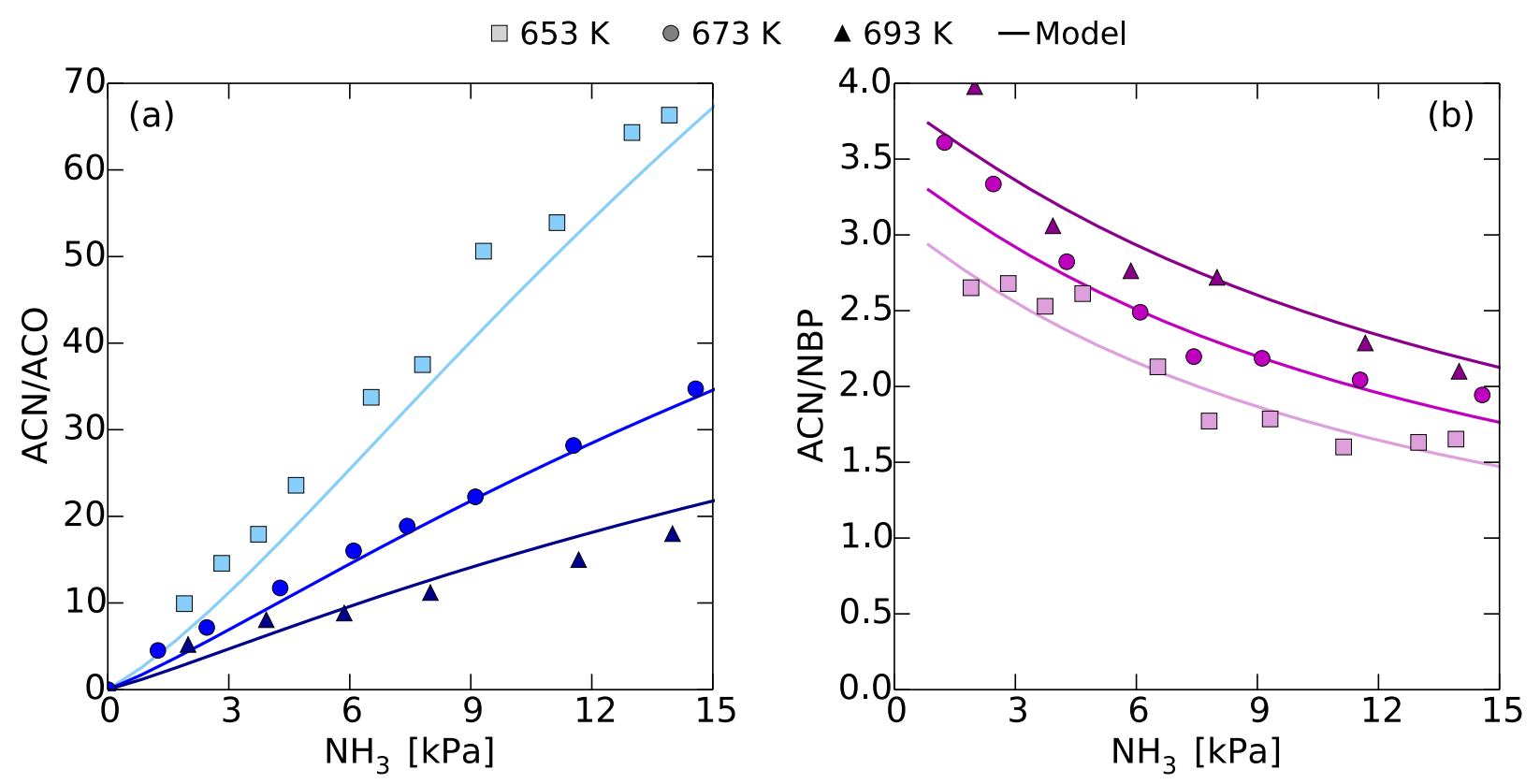

Fig. 12. Dependence of the product ratios (a) ACN/ACO and (b) ACN/BNP on the feed ammonia partial pressure for three different temperatures. $\mathrm{P}_{\mathrm{C} 3 \mathrm{H} 6}=8.0 \mathrm{kPa}$ and $\mathrm{P}_{\mathrm{O} 2}=16.3 \mathrm{kPa}$. $653 \mathrm{~K}$ (light color, 口) with $\mathrm{C}_{3} \mathrm{H}_{6}$ conversion $0.9 \% \pm 0.1 \%$; $673 \mathrm{~K}$ (medium color, ๑) with $\mathrm{C}_{3} \mathrm{H}_{6}$ conversion $0.8 \% \pm 0.1 \%$; and $693 \mathrm{~K}$ (dark color, $\boldsymbol{\Delta}$ ) with $\mathrm{C}_{3} \mathrm{H}_{6}$ conversion $1.0 \% \pm 0.1 \%$. Symbols are data points; lines are calculated from the reaction network model.

As discussed in the Introduction, both theoretical calculations on a small $\mathrm{Mo}^{6+}$ cluster $\left(\Delta \mathrm{G}_{673 \mathrm{~K}}=12.4 \mathrm{kcal} / \mathrm{mol}\right.$ for $\left.(\mathrm{O}=\mathrm{Mo}=\mathrm{O}) \mathrm{MoCl}_{2}+\mathrm{NH}_{3} \rightarrow(\mathrm{O}=\mathrm{Mo}=\mathrm{NH}) \mathrm{MoCl}_{2}+\mathrm{H}_{2} \mathrm{O}\right)[34]$ and the organometallic literature involving $\mathrm{Mo}^{6+}$ complexes with imine ligands $[35,36,37]$ indicate that $\mathrm{Mo}^{6+}=\mathrm{NH}$ groups are not thermodynamically stable in the presence of water, and are therefore likely to be destroyed by reaction with water. Consistent with these observations, we have calculated the free energy change for the reaction $(\mathrm{O}=\mathrm{Mo}=\mathrm{O})_{2} \mathrm{Bi}_{2} \mathrm{O}_{10} \mathrm{H}_{10}+\mathrm{NH}_{3} \rightarrow$ $(\mathrm{O}=\mathrm{Mo}=\mathrm{NH})(\mathrm{O}=\mathrm{Mo}=\mathrm{O}) \mathrm{Bi}_{2} \mathrm{O}_{10} \mathrm{H}_{10}+\mathrm{H}_{2} \mathrm{O}$ to be a substantial $18.2 \mathrm{kcal} / \mathrm{mol}$. Since ammonia oxidation to $\mathrm{N}_{2}$ is significantly suppressed by water, we propose that low concentrations of $\mathrm{Mo}=\mathrm{NH}$ or other $\mathrm{M}-\mathrm{NH}_{2}\left(\mathrm{M}=\mathrm{Bi}^{3+}\right.$ or $\left.\mathrm{Mo}^{6+}\right)$ species may be involved in $\mathrm{N}_{2}$ formation. For example, it is possible to envision the reaction of $\mathrm{Mo}=\mathrm{NH}$ with $\mathrm{NH}_{3}$ to form hydrazine, which then could react further to produce $\mathrm{N}_{2}$ and $\mathrm{H}_{2} \mathrm{O}$. For such a pathway to be viable, the activation 
barrier to form hydrazine would have to be low in order to compensate for the expected low concentration of the water sensitive $\mathrm{Mo}=\mathrm{NH}$ groups. This proposed pathway to $\mathrm{N}_{2}$ is admittedly speculative and, therefore, further research would need to be conducted in order to gain additional mechanistic insight into the ammonia oxidation reaction.

We note that $\mathrm{Mo}=\mathrm{NH}$ groups may also be responsible for the $\sim 1.6 \mathrm{x}$ rate enhancement in the rate of propene oxidation and ammoxidation observed after catalyst pretreatment in $\mathrm{NH}_{3}$ and $\mathrm{O}_{2}$ (see Table 2). If we assume that the rate-limiting step of alpha hydrogen abstraction from propene could occur with equal probability at either an $\mathrm{Mo}=\mathrm{O}$ site with activation energy $\xi$ $\mathrm{kcal} / \mathrm{mol}$ or at a $\mathrm{Mo}=\mathrm{NH}$ site with activation energy $\xi-10 \mathrm{kcal} / \mathrm{mol}$, both with the same activation entropy and thus the same pre-exponential factor, then only $1 \mathrm{Mo}=\mathrm{NH}$ site per $1100 \mathrm{Mo}=\mathrm{O}$ sites would result in a 1.6x rate enhancement. Therefore, a contribution to propene activation from a very low concentration of metastable $\mathrm{Mo}=\mathrm{NH}$ groups could explain both the observed $\sim 1.6 \mathrm{x}$ increase in steady state propene consumption rate after prolonged exposure to $\mathrm{NH}_{3}$, as well as the removal of said rate enhancement after subsequent treatment with a high partial pressure of water (see Table 2). In support of this proposal, we note that Goddard et al. have reported that $\mathrm{Mo}=\mathrm{NH}$ groups are better hydrogen abstraction sites than $\mathrm{Mo}=\mathrm{O}$ groups, and that the activation barrier for hydrogen abstraction by an $\mathrm{Mo}=\mathrm{NH}$ group is $\sim 10 \mathrm{kcal} / \mathrm{mol}$ lower than that for hydrogen abstraction by a $\mathrm{Mo}=\mathrm{O}$ group [36]. Using our $(\mathrm{O}=\mathrm{Mo}=\mathrm{O})_{2} \mathrm{Bi}_{2} \mathrm{O}_{10} \mathrm{H}_{10}$ cluster, which is a more accurate approximation of the surface of $\mathrm{Bi}_{2} \mathrm{Mo}_{3} \mathrm{O}_{12}$, we find the $\mathrm{H}$ radical addition energy, which is correlated with the energy required for hydrogen abstraction [6], to be $13.0 \mathrm{kcal} / \mathrm{mol}$ greater for $\mathrm{Mo}=\mathrm{O}$ than for $\mathrm{Mo}=\mathrm{NH}$. Therefore, we consider it plausible that a very low concentration of surface $\mathrm{Mo}=\mathrm{NH}$ groups could contribute to the enhanced activity for propene 
consumption during propene oxidation and ammoxidation over $\mathrm{Bi}_{2} \mathrm{Mo}_{3} \mathrm{O}_{12}$ pretreated in $\mathrm{NH}_{3}$ and $\mathrm{O}_{2}$ under conditions where the water partial pressure is relatively low.

\subsection{Chemical justification for the proposed propene ammoxidation mechanism}

Previous studies of propene oxidation and ammoxidation have found that the ratelimiting step for both reactions involves cleavage of one of the C-H bonds of the methyl group of propene $[11,12,29]$. The results presented here are fully consistent with this conclusion. The kinetics of propene consumption during oxidation and ammoxidation are identical; for both reactions, the rate is first order in the partial pressure of propene and zero order in the partial pressure of oxygen, and in the case of propene ammoxidation, zero order in the partial pressure of ammonia (see Fig. 1). Likewise, the apparent activation energies for propene oxidation and ammoxidation are essentially the same (see Table 4). Whereas earlier studies have suggested that the rate-limiting step occurs on oxygen atoms associated with bismuth $[8,9,10]$, our recent experimental and theoretical work on propene oxidation provides compelling evidence that the active site is a molybdenyl oxo group $(\mathrm{Mo}=\mathrm{O})$ perturbed electronically by a neighboring bismuth atom $[16,26]$. We therefore propose that activation of propene during propene ammoxidation occurs on the same site.

Our proposed mechanism for propene oxidation has been discussed previously [16,26], and therefore will only be summarized here. The allyl radical formed upon propene activation rapidly reacts with a $\mathrm{Mo}=\mathrm{O}$ group to form a Mo-bound allyl alkoxide species (intermediate I), which then undergoes hydrogen abstraction to produce coordinated acrolein at a reduced site (intermediate $\mathrm{I}_{\mathrm{O}}$ ) As discussed below, the Gibbs free energy of activation for hydrogen abstraction from Mo-bound allyl alkoxide species is high. Acrolein coordinated at a reduced site 
is susceptible to attack by adsorbed oxygen atoms to produce the oxygen-containing byproducts, prior to undergoing what Goddard found to be unfavorable acrolein desorption [38]. We note that these byproducts have been reported previously to derive primarily from an adsorbed acrolein precursor, and not via secondary combustion of acrolein $[12,26]$. Previous work in our group has found that $\mathrm{CO}_{2}$ production is 0.5 order in the partial pressure of oxygen [26], therefore, since $\mathrm{CO}_{2}$ accounts for more than $50 \%$ of the oxygen-containing byproducts at all ammonia pressures (see Fig. 4), we treat the reaction of intermediate $I_{O}$ to form oxygencontaining byproducts as dependent on the $\mathrm{O}_{2}$ partial pressure to the 0.5 power. Since we are proposing that the catalyst surface is relatively unchanged upon ammonia exposure, the primary pathways to both acrolein and the oxygen-containing byproducts are assumed to occur via the same pathways when ammonia is present. We have indicated these two reactions in the top half of Scheme 1.

Since the oxidation and ammoxidation have a common initial, rate-limiting step from propene, but acrylonitrile is not formed from ammoxidation of acrolein, $\mathrm{NH}_{3}$ must react with a hydrocarbon intermediate to form an acrylonitrile precursor. This reactive hydrocarbon intermediate could be either the physisorbed allyl radical or the Mo-bound allyl alkoxide species $\left(\mathrm{Mo}^{5+}-\mathrm{OCH}_{2} \mathrm{CH}=\mathrm{CH}_{2}\right)$, or both. The Mo-bound allyl alkoxide is the most likely species to react with adsorbed ammonia, since theoretical studies by Goddard et al. using a molybdate molecular cluster report that the Gibbs free energy of activation for the hydrogen abstraction from a Mobound allyl alkoxide to produce coordinated acrolein (viz. $\mathrm{Mo}^{6+}=\mathrm{O}+\mathrm{Mo}^{5+}-\mathrm{OCH}_{2} \mathrm{CH}=\mathrm{CH}_{2} \rightarrow$ $\left.\mathrm{Mo}^{5+}-\mathrm{OH}+\mathrm{Mo}^{4+} \leftarrow \mathrm{O}=\mathrm{CHCH}=\mathrm{CH}_{2}\right)$ is quite substantial $\left(\Delta \mathrm{G}^{\ddagger}{ }_{593 \mathrm{~K}}=37.5 \mathrm{kcal} / \mathrm{mol}\right)$ [38]. Theoretical studies in our own group on the (010) surface of $\mathrm{Bi}_{2} \mathrm{Mo}_{3} \mathrm{O}_{12}$ also find that this second hydrogen abstraction is the second most energetically difficult step in the production of acrolein 
[16]. Therefore, Mo-bound allyl alkoxide species should be the longest-lived propene-derived intermediates, making them prime candidates for reaction with $\mathrm{NH}_{3}$ adsorbed on nearby $\mathrm{Bi}^{3+}$ cations. We propose that if $\mathrm{NH}_{3}$ adsorbs near a $\mathrm{Mo}^{5+}-\mathrm{OCH}_{2} \mathrm{CH}=\mathrm{CH}_{2}$ and reacts with it before it undergoes the difficult hydrogen abstraction, an acrylonitrile precursor would form. For this proposed reaction mechanism, the ratio of acrylonitrile to acrolein should be approximately first order in $\mathrm{NH}_{3}$ pressure at low conversion, since at low coverage, adsorption is first order in the adsorbent pressure. An approximately first order dependence is indeed observed experimentally (see Fig. 12 (a)). We also note that the reaction with adsorbed ammonia must be energetically more favorable than hydrogen abstraction, in order to account for the observed high selectivity to acrylonitrile even at very low partial pressures of ammonia (see Fig. 5 (a)). In the bottom half of Scheme 1, we include a pathway from intermediate I (Mo-bound allyl alkoxide) to a carbonnitrogen intermediate $\left(I_{N}\right)$ that becomes relevant when ammonia is present in the feed and is first order in ammonia partial pressure.

Based on the preceding discussion, we hypothesize that the carbon-nitrogen intermediate $\left(\mathrm{I}_{\mathrm{N}}\right.$ ) formed by the reaction of adsorbed $\mathrm{NH}_{3}$ and $\mathrm{Mo}^{5+}-\mathrm{OCH}_{2} \mathrm{CH}=\mathrm{CH}_{2}$ may be adsorbed allylamine $\left(\mathrm{Mo}^{5+}-\mathrm{OCH}_{2} \mathrm{CH}=\mathrm{CH}_{2}+\mathrm{Bi}^{3+} \leftarrow: \mathrm{NH}_{3} \rightarrow \mathrm{Mo}^{5+}-\mathrm{OH}+\mathrm{Bi}^{3+} \leftarrow: \mathrm{NH}_{2} \mathrm{CH}_{2} \mathrm{CH}=\mathrm{CH}_{2}\right)$. Previous researchers have investigated the reaction of allylamine over $\mathrm{Bi}_{2} \mathrm{Mo}_{3} \mathrm{O}_{12}$, though they considered it as a probe molecule, not a potential intermediate [46]. They reported that allylamine, both with and without co-fed ammonia, converts mainly to acrylonitrile, propionitrile, and acetonitrile, though with much higher yields of propionitrile than we observe. Their experiments with 1,1- $\mathrm{d}_{2}$-allylamine produce almost exclusively $\mathrm{d}_{0}$ acrylonitrile, indicating the $-\mathrm{CN}$ group of allylamine remains intact during reaction. Our data for the reaction of allylamine is presented in Table 3. We observe that in the presence of oxygen, allylamine will 
form acrylonitrile with reasonably high selectivity, as well as acrolein and the nitrogencontaining byproducts. When ammonia is co-fed with allylamine and oxygen, the selectivity to the nitrogen-containing byproducts increases significantly, and all the product ratios are comparable to what is observed during propene ammoxidation. While these observations support the plausibility of adsorbed allylamine as a possible intermediate, without direct observation of during propene ammoxidation, they are not sufficient to prove that allylamine is indeed an intermediate.

We propose four separate pathways by which the intermediate $I_{N}$ can form observable products. The most important of these is a series of four hydrogen abstractions that eventually produce acrylonitrile. If $\mathrm{I}_{\mathrm{N}}$ is indeed allylamine, we know from gas phase bond dissociation energy (BDE) calculations that the $\alpha-\mathrm{H}$ of allylamine is quite weak ( $82 \mathrm{kcal} / \mathrm{mol}$, versus 93 $\mathrm{kcal} / \mathrm{mol}$ for the $\alpha-\mathrm{H}$ of propene). Abstraction of this $\mathrm{H}$ atom leaves a $\mathrm{NH}_{2}$-stabilized allyl species, which could undergo three additional hydrogen abstractions in a number of possible mechanisms to produce the very thermodynamically favorable acrylonitrile $\left(\mathrm{NH}_{2}-\mathrm{CH}_{2}-\mathrm{CH}=\mathrm{CH}_{2}\right.$ $\left.+1 / 2 \mathrm{O}_{2} \rightarrow \mathrm{NC}-\mathrm{CH}=\mathrm{CH}_{2}+\mathrm{H}_{2} \mathrm{O} ; \Delta \mathrm{G}_{673 \mathrm{~K}}=-104 \mathrm{kcal} / \mathrm{mol}\right)$.

Two different routes from $I_{N}$ to nitrogen-containing byproducts are proposed. The first of these involves interaction with ammonia, possibly via addition of adsorbed $\mathrm{NH}_{3}$ across the C-C bond of allylamine to create two $\mathrm{CN}$ fragments. The gas phase free energy for reaction of allylamine and ammonia to form methylamine and ethenamine is close to thermoneutral $\left(\Delta \mathrm{G}_{673 \mathrm{~K}}\right.$ $=+3.7 \mathrm{kcal} / \mathrm{mol}$ ), and can be driven by the extremely favorable oxidative dehydrogenations to make $\mathrm{HCN}$ or acetonitrile and water $\left(\Delta \mathrm{G}_{673 \mathrm{~K}}=-95 \mathrm{kcal} / \mathrm{mol}\right.$ and $-63 \mathrm{kcal} / \mathrm{mol}$, respectively). Note that 1,2-diaminopropane, the Markovnikov product of $\mathrm{NH}_{3}$ addition across the $\mathrm{C}=\mathrm{C}$ bond of allylamine, has a higher gas phase free energy of formation from allylamine $\left(\Delta \mathrm{G}_{673 \mathrm{~K}}=+11.2\right.$ 
$\mathrm{kcal} / \mathrm{mol}$ ) than the $\mathrm{C}-\mathrm{C}$ cleavage products, and that 1,2-diaminopropane decomposition was not observed experimentally (see Table 3). Since the observed ratio of $\mathrm{HCN}$ to acetonitrile ratio is 5:2, but we do not observe acetonitrile decomposition to $\mathrm{HCN}$ (Table 3), a fraction of the ethenamine (or some derivative prior to acetonitrile) must undergo additional attack by $\mathrm{NH}_{3}$ to create two $1 \mathrm{C}-1 \mathrm{~N}$ fragments that both become $\mathrm{HCN}$ in a thermodynamically favorable process. We note that since the ratio of acrylonitrile to the nitrogen-containing byproducts does not depend on ammonia partial pressure to the negative first power, but rather to a fractional negative power (see Fig. 12 (b)), a second route to the nitrogen-containing byproducts, one not requiring ammonia, is also needed.

This second proposed route to nitrogen-containing byproducts involves attack by adsorbed oxygen atoms, in a reaction similar to the one we propose to produce the oxygencontaining byproducts. The exact mechanism for such a reaction is unclear and difficult to probe experimentally. Nevertheless, some process involving $\mathrm{O}$ to perform $\mathrm{C}-\mathrm{C}$ bond cleavage and eventually produce the nitrogen-containing byproducts is necessary to explain the observed $\sim 0.5$ order in oxygen partial pressure (see Fig. 6 (a)). If $\mathrm{I}_{\mathrm{N}}$ is allylamine, C-C bond scission should be relatively facile, since the $\mathrm{BDE}$ of this bond is only $96 \mathrm{kcal} / \mathrm{mol}$ as compared to the $\mathrm{C}-\mathrm{C}$ bond of either propene or acrolein $(\mathrm{BDE}=107$ and $101 \mathrm{kcal} / \mathrm{mol}$ respectively). After the carbon-carbon bond scission event involving $\mathrm{I}_{\mathrm{N}}$ and $\mathrm{O}$, the fragments would need to incorporate additional $\mathrm{NH}_{3}$ in order to create the nitrogen-containing byproducts.

We also include an additional pathway involving reaction of $\mathrm{I}_{\mathrm{N}}$ with water to produce acrolein, in order to account for the observed increase in acrolein selectivity when water is added to the feed when either propene or allylamine is the reactant. The C-N bond of allylamine is actually its weakest bond having a BDE of $76 \mathrm{kcal} / \mathrm{mol}$, so this bond may break upon interaction 
with water to generate an acrolein precursor. A possible pathway for this is the approximately thermoneutral reaction of allylamine and water to create allyl alcohol and ammonia $\left(\mathrm{H}_{2} \mathrm{C}=\mathrm{CH}-\right.$ $\left.\mathrm{CH}_{2}-\mathrm{NH}_{2}+\mathrm{H}_{2} \mathrm{O} \rightarrow \mathrm{H}_{2} \mathrm{C}=\mathrm{CH}-\mathrm{CH}_{2}-\mathrm{OH}+\mathrm{NH}_{3} ; \Delta \mathrm{G}_{673 \mathrm{~K}}=+1.3 \mathrm{kcal} / \mathrm{mol}\right)$, followed by the thermodynamically very favorable reaction of allyl alcohol and oxygen to produce acrolein and water $\left(\mathrm{H}_{2} \mathrm{C}=\mathrm{CH}-\mathrm{CH}_{2}-\mathrm{OH}+\mathrm{O}_{2} \rightarrow \mathrm{H}_{2} \mathrm{C}=\mathrm{CH}-\mathrm{CHO}+\mathrm{H}_{2} \mathrm{O} ; \Delta \mathrm{G}_{673 \mathrm{~K}}=-53 \mathrm{kcal} / \mathrm{mol}\right)$. The conversion of allyl alcohol to acrolein with high selectivity, as well as the slight conversion of allylamine to acrolein in the presence of water, has been reported previously [46,47].

Additionally, in agreement with previous reports [27,28], we find that acrolein reacts in the presence of ammonia to form acrylonitrile (see Table 3). The reactivity of acrolein with ammonia is further confirmed by the results shown in Fig. 10, which illustrates the intrinsic firstorder dependencies of acrolein reaction to acrylonitrile on the partial pressures of both acrolein and ammonia. A small amount of nitrogen-containing byproducts are observed when acrolein is the reactant; however, the selectivity is an order of magnitude lower than the selectivity to acrylonitrile. Therefore, to a first approximation, the secondary reaction of acrolein to NBP can be neglected. Considering the selectivity versus conversion data presented in Fig. 9, the small, but non-zero, influence of the secondary pathway from acrolein to acrylonitrile is directly observable at low conversion. Inclusion of this reaction in our network completes the pathways for Scheme 1.

The final reaction occurring during propene ammoxidation is the parasitic oxidation of ammonia to nitrogen gas. Selective catalytic oxidation (SCO) of ammonia has been found to occur over many different metal oxides, including $\mathrm{Bi}_{2} \mathrm{MoO}_{6}$ and molybdenum oxides with and without $\mathrm{Bi}$ or $\mathrm{Pb}$ doping $[40,48]$. Previous studies have found these reactions to be first order in ammonia and zero order in oxygen partial pressures, and to be inhibited by water, though not 
suppressed to nearly the degree observed during propene ammoxidation over $\mathrm{Bi}_{2} \mathrm{Mo}_{3} \mathrm{O}_{12}$. As discussed in Section 4.1, we propose that $\mathrm{N}_{2}$ formation involves the reaction of gas-phase ammonia with surface $\mathrm{M}-\mathrm{NH}_{\mathrm{x}}$ groups $(\mathrm{M}=\mathrm{Bi}, \mathrm{Mo} ; \mathrm{x}=1,2)$. Destruction of these groups upon contact with water can explain the significant suppression of the rate of $\mathrm{N}_{2}$ formation upon cofeeding even a moderate concentration of water, even though the rate of propene consumption is not affected. Regardless of how $\mathrm{N}_{2}$ is formed, the rate of formation of this product can be modeled empirically by Eqn. 4. This rate expression involves two rate coefficients, $\mathrm{k}_{\mathrm{N} 2}$ and $\mathrm{k}_{\mathrm{H} 22}$, which we do not attempt to interpret chemically.

$$
r_{N_{2}}=\frac{k_{N_{2}} P_{N H 3}}{1+k_{H_{2} O} P_{H 2 O}}
$$

\subsection{Reaction network model}

The reaction network given in Scheme 1 was used to develop a model for the kinetics of propene ammoxidation. Expressions for propene consumption and for ammonia oxidation to $\mathrm{N}_{2}$ are described by Eqns. 3 and 4, respectively. Based on the discussion presented in Section 3.2.3, a rate expression for acrolein ammoxidation to acrylonitrile can be written as $\mathrm{k}_{\mathrm{ACON}} \mathrm{P}_{\mathrm{ACO}} \mathrm{P}_{\mathrm{NH} 3}$. By applying the pseudo-steady-state approximation to the three intermediate species, $\mathrm{I}, \mathrm{I}_{\mathrm{O}}$, and $\mathrm{I}_{\mathrm{N}}$, the remaining reactions can be described by five linearly independent selectivity ratios. As shown in Scheme 1, these are: $\alpha \mathrm{P}_{\mathrm{NH} 3}$, the ratio of the rate at which $\mathrm{I}$ is converted to $\mathrm{I}_{\mathrm{N}}$ relative to the rate at which it is converted to $\mathrm{I}_{\mathrm{O}} ; \beta \mathrm{P}_{\mathrm{O} 2}{ }^{0.5}$, the ratio of the rate at which $\mathrm{I}_{\mathrm{O}}$ is converted to the oxygen-containing byproducts relative to the rate at which it is converted to acrolein; $\gamma \mathrm{P}_{\mathrm{H} 2 \mathrm{O}}$, the ratio of the rate at which $I_{N}$ is converted to acrolein relative to the rate at which it is converted to acrylonitrile; $\delta \mathrm{P}_{\mathrm{NH} 3}$, the ratio of the rate at which $\mathrm{I}_{\mathrm{N}}$ is converted to the nitrogen-containing byproducts with $\mathrm{NH}_{3}$ relative to the rate at which it is converted to acrylonitrile; and $\varepsilon \mathrm{Po}_{2}{ }^{0.5}$, the ratio of the rate at which $\mathrm{I}_{\mathrm{N}}$ is converted to nitrogen-containing byproducts with $\mathrm{O}_{2}$ relative to the 
rate at which it is converted to acrylonitrile. The abovementioned parameters are used in the overall rate expressions given by Eqns. 5-8. We should note that, since the selectivity to the oxygen-containing byproducts at all conditions was $>6 \%$, we assume that $6 \%$ of the fed propene goes to these products. In this way, the selectivity to the oxygen-containing byproducts will exhibit the observed $>50 \%$ decrease in selectivity upon addition of the lowest experimentallyattainable $\mathrm{NH}_{3}$ partial pressure, and still be finite when $\mathrm{P}_{\mathrm{NH} 3}$ is high.

$$
\begin{aligned}
& r_{A C N}=0.94 k_{R L S} P_{C 3 H 6}\left(\frac{\alpha P_{N H 3}}{1+\alpha P_{N H 3}}\right)\left(\frac{1}{1+\gamma P_{H 2 O}+\delta P_{N H 3}+\varepsilon P_{O 2}{ }^{0.5}}\right)+k_{A C O N} P_{A C O} P_{N H 3} \\
& r_{N B P}=0.94 k_{R L S} P_{C 3 H 6}\left(\frac{\alpha P_{N H 3}}{1+\alpha P_{N H 3}}\right)\left(\frac{\delta P_{N H 3}+\varepsilon P_{O 2}{ }^{0.5}}{1+\gamma P_{H 2 O}+\delta P_{N H 3}+\varepsilon P_{O 2}{ }^{0.5}}\right) \\
& r_{A C O}=0.94 k_{R L S} P_{C 3 H 6}\left[\left(\frac{1}{1+\alpha P_{N H 3}}\right)\left(\frac{1}{1+\beta P_{O 2}{ }^{0.5}}\right)+\left(\frac{\alpha P_{N H 3}}{1+\alpha P_{N H 3}}\right)\left(\frac{\gamma P_{H 2 O}}{1+\gamma P_{H 2 O}+\delta P_{N H 3}+\varepsilon P_{O 2}{ }^{0.5}}\right)\right]- \\
& k_{A C O N} P_{A C O} P_{N H 3} \\
& r_{O B P}=0.94 k_{R L S} P_{C_{3} H_{6}}\left(\frac{1}{1+\alpha P_{N H 3}}\right)\left(\frac{\beta P_{O 2}{ }^{0.5}}{1+\beta P_{O 2}{ }^{0.5}}\right)+0.06 k_{R L S} P_{C_{3} H_{6}}
\end{aligned}
$$

Eqns. 3-8 were incorporated into a steady-state, one-dimensional, plug-flow reactor model that was used to calculate the conversion of propene, ammonia and oxygen to various products. An integral reactor model was needed to account for changes in the concentrations of ammonia and water through the reactor, even though the conversion of propene was small. The rate parameters appearing in the model were determined by fitting the selectivity outputs to the observed selectivity data at the experimentally observed propene conversion. More details about the modeling process are given in the Supporting Information.

The rate parameters were fit initially to selectivity data obtained at $673 \mathrm{~K}$, and then extended to other temperatures by fitting an activation energy and setting the pre-exponential factor to give the previously optimized rate parameter determined for $673 \mathrm{~K}$. Table 5 lists the activation energies and pre-exponential factors for all of the rate coefficients described above. 
Values of the pre-exponential factor and the activation energy for $\mathrm{k}_{\mathrm{RLS}}$ were obtained from the Arrhenius plot (see Supporting Information), and the activation energy for $\mathrm{k}_{\mathrm{ACON}}$ was taken from the literature [26]. All other values were obtained by fitting the model to the data. It is evident from the solid curves in Figs. 5, 6, 8, 9, 11, and 12 that, while not perfect, the model does a good job of describing the trends in the experimental data as a function of all partial pressures, conversions and temperatures investigated.

\begin{tabular}{cccc} 
& Ea $(\mathrm{kcal} / \mathrm{mol})$ & $\mathrm{A}$ & Units of A \\
\hline \hline $\mathrm{k}_{\mathrm{RLS}}$ & 22.4 & 2.3 & $\mathrm{~mol} / \mathrm{s} / \mathrm{m}^{2} / \mathrm{kPa}$ \\
\hline $\mathrm{k}_{\mathrm{ACON}}$ & 7 & $6 \times 10^{-04}$ & $\mathrm{~mol} / \mathrm{s} / \mathrm{m}^{2} / \mathrm{kPa}^{2}$ \\
\hline $\mathrm{k}_{\mathrm{N} 2}$ & 35 & $9 \times 10^{5}$ & $\mathrm{~mol} / \mathrm{s}^{2} / \mathrm{m}^{2} / \mathrm{kPa}$ \\
\hline $\mathrm{k}_{\mathrm{H} 2 \mathrm{O}}$ & 2 & $5 \times 10^{1}$ & $\mathrm{~mol} / \mathrm{s} / \mathrm{m}^{2} / \mathrm{kPa}$ \\
\hline$\alpha$ & -15 & $3 \times 10^{-05}$ & $\mathrm{~mol} / \mathrm{s} / \mathrm{m}^{2} / \mathrm{kPa}$ \\
\hline$\beta$ & -5 & $2 \times 10^{-03}$ & $\mathrm{~mol} / \mathrm{s} / \mathrm{m}^{2} / \mathrm{kPa}$ \\
\hline$\gamma$ & 10 & 2 & $\mathrm{~mol} / \mathrm{s} / \mathrm{m}^{2} / \mathrm{kPa}$ \\
\hline$\delta$ & -10 & $1 \times 10^{-05}$ & $\mathrm{~mol} / \mathrm{s} / \mathrm{m}^{2} / \mathrm{kPa}$ \\
\hline$\varepsilon$ & -5 & $2 \times 10^{-03}$ & $\mathrm{~mol} / \mathrm{s} / \mathrm{m}^{2} / \mathrm{kPa}$
\end{tabular}

Table 5. Values of the activation energy $\mathrm{E}_{\mathrm{a}}$ and the pre-exponential factor $\mathrm{A}$ for each of the reactions and selectivity ratios shown in Scheme 1.

Our values for $\mathrm{k}_{\mathrm{RLS}}\left(1 \times 10^{-7} \mathrm{~mol} / \mathrm{s} / \mathrm{m}^{2} / \mathrm{kPa}\right)$ and $\mathrm{k}_{\mathrm{ACON}}\left(3 \times 10^{-6} \mathrm{~mol} / \mathrm{s} / \mathrm{m}^{2} / \mathrm{kPa}^{2}\right)$ calculated from the Arrhenius parameters at $673 \mathrm{~K}$ for $\mathrm{Bi}_{2} \mathrm{Mo}_{3} \mathrm{O}_{12}$ are within an order of magnitude of those reported by Wragg et al. for propene and acrolein ammoxidation over a different catalyst with Bi:Mo of $0.73: 1$ at $673 \mathrm{~K}$, though their rate law for acrolein ammoxidation did not involve $\mathrm{P}_{\mathrm{NH} 3}$ $\left(\mathrm{k}_{\mathrm{RLS}}=5 \times 10^{-8} \mathrm{~mol} / \mathrm{s} / \mathrm{m}^{2} / \mathrm{kPa}\right.$ assuming a BET surface area of $1.0 \mathrm{~m}^{2} / \mathrm{g} ; \mathrm{k}_{\mathrm{ACON}}=6 \times 10^{-7}$ $\mathrm{mol} / \mathrm{s} / \mathrm{m}^{2} / \mathrm{kPa}^{2}$ assuming a BET surface area of $1.0 \mathrm{~m}^{2} / \mathrm{g}$ and dividing out a $\mathrm{P}_{\mathrm{NH} 3}=20$ torr) [28]. The large activation energy associated with $\mathrm{k}_{\mathrm{N} 2}$ indicates that critical step in the oxidation of ammonia is demanding, consistent with the high BDE of the $\mathrm{N}-\mathrm{H}$ bonds in $\mathrm{NH}_{3}(114.1$ 
$\mathrm{kcal} / \mathrm{mol}$ ). Our $\mathrm{N}_{2}$ activation energy is in agreement with the value reported by Matsuura for first order ammonia oxidation to $\mathrm{N}_{2}$ over $\mathrm{Bi}_{2} \mathrm{MoO}_{6}(37 \mathrm{kcal} / \mathrm{mol})$ [40].

Similar to the results of previous studies that find acrylonitrile is mostly produced from primary reaction of propene [27,28], our model predicts that, at stoichiometric feed conditions, $673 \mathrm{~K}$ and $1 \%$ conversion, only $\sim 5 \%$ of the outlet acrylonitrile is produced via acrolein. This is equivalent to $\sim 50 \%$ of the acrolein generated in the reactor being converted to acrylonitrile in secondary reaction, consistent with the low activation energy for acrolein to acrylonitrile reaction. At these same conditions (stoichiometric feed, $673 \mathrm{~K}, 1 \%$ conversion), our model predicts that approximately one third of the produced acrolein is from reaction of $\mathrm{I}_{\mathrm{N}}$ and $\mathrm{H}_{2} \mathrm{O}$, with the remainder coming via $\mathrm{I}_{\mathrm{O}}$. We also find that the majority $(\sim 2 / 3)$ of the nitrogencontaining byproducts are produced from $\mathrm{I}_{\mathrm{N}}$ via initial reaction with adsorbed oxygen, rather than initial reaction with $\mathrm{NH}_{3}$.

The negative activation energies for $\beta, \delta$, and $\varepsilon$ demonstrate that higher temperatures favor the three-carbon products over the one- and two-carbon products. Grasselli et al. also found that the formation of acrylonitrile during ammoxidation and acrolein during oxidation relative to $\mathrm{CO}_{2}$ is favored at higher temperatures on $\mathrm{Bi}_{2} \mathrm{Mo}_{3} \mathrm{O}_{12}$ [14]. A large, negative value for the activation energy associated with $\alpha$ is found, which accounts for the higher observed selectivity to acrolein during ammoxidation at high temperatures (see Fig. 11(a)). This negative sign and the magnitude of this activation energy reflect the substantially higher activation energy for hydrogen abstraction from allyl alkoxide to produce (primarily) acrolein compared to reaction with adsorbed $\mathrm{NH}_{3}$ to produce (primarily) acrylonitrile. This pattern is consistent with the theoretical analysis showing that hydrogen abstraction from allyl alkoxide is a difficult process $[16,38]$, and implies that reaction of the allyl alkoxide with adsorbed ammonia is facile. 


\section{Conclusions}

This study provides new insights into the mechanism of propene ammoxidation over $\mathrm{Bi}_{2} \mathrm{Mo}_{3} \mathrm{O}_{12}$, and in particular the manner in which reaction conditions affect the distribution of products. Our results confirm that the kinetics of ammoxidation are first order in propene partial pressure and zero order in both oxygen (for $\mathrm{O}_{2} / \mathrm{C}_{3} \mathrm{H}_{6}>1.5$ ) and ammonia partial pressures, and that the apparent activation energy for propene consumption is $\sim 22 \mathrm{kcal} / \mathrm{mol}$ for both propene oxidation and ammoxidation. The similarity in the activation energy and the dependence on only propene partial pressure for both propene oxidation and ammoxidation suggests that both reactions occur via a common rate-limiting step, in good agreement with prior studies.

We propose that two types of $\mathrm{N}$-containing species are involved in propene ammoxidation: one that is extremely sensitive to water and one that is not. $\mathrm{NH}_{3}$ adsorbed on $\mathrm{Bi}^{3+}$ ions is taken to be the $\mathrm{N}$-containing species responsible for $\mathrm{C}-\mathrm{N}$ bond formation. DFT calculations suggest that under the conditions of our experiments, the occupancy of $\mathrm{Bi}^{3+}$ cations by adsorbed $\mathrm{NH}_{3}$ is low, but non-zero, and that $\mathrm{NH}_{3}$ adsorption is insensitive to the presence of water. Additional DFT calculations indicate that $\mathrm{Mo}^{6+}=\mathrm{NH}$ groups are highly unstable thermodynamically in the presence of water. Therefore, we propose that surface $\mathrm{M}-\mathrm{NH}_{\mathrm{x}}(\mathrm{M}=\mathrm{Bi}$, Mo; $\mathrm{x}=1,2$ ) species are responsible for $\mathrm{NH}_{3}$ oxidation to $\mathrm{N}_{2}$, a reaction that can be completely suppressed by moderate partial pressures of water. The unlikelihood of $\mathrm{Mo}=\mathrm{NH}$ groups participating in the formation of $\mathrm{C}-\mathrm{N}$ bonds is supported by our observation that the formation of acrylonitrile and other $\mathrm{N}$-containing compounds is unaffected by the presence of water.

We hypothesize that the $\mathrm{C}-\mathrm{N}$ bond formation during propene ammoxidation may proceed via the reaction $\mathrm{Mo}^{5+}-\mathrm{OCH}_{2} \mathrm{CH}=\mathrm{CH}_{2}+\mathrm{Bi}^{3+} \leftarrow: \mathrm{NH}_{3} \rightarrow \mathrm{Mo}^{5+}-\mathrm{OH}+\mathrm{Bi}^{3+} \leftarrow: \mathrm{NH}_{2} \mathrm{CH}_{2} \mathrm{CH}=\mathrm{CH}_{2}$. 
While the product of this reaction, allylamine, was not observed as an intermediate, introduction of allylamine together with ammonia and oxygen produces a product distribution very similar to that observed during propene ammoxidation. The reaction leading to allyamine is thought to compete with that leading to acrolein $\left(\mathrm{Mo}^{6+}=\mathrm{O}+\mathrm{Mo}^{5+}-\mathrm{OCH}_{2} \mathrm{CH}=\mathrm{CH}_{2} \rightarrow \mathrm{Mo}^{5+}-\mathrm{OH}+\right.$ $\mathrm{Mo}^{4+} \leftarrow \mathrm{O}=\mathrm{CHCH}=\mathrm{CH}_{2}$ ). Even at low partial pressures of ammonia and low conversion, the selectivity to acrylonitrile dominates that to acrolein, indicating that the former reaction is preferred over the later. We have also shown, in agreement with previous researchers [27], that while acrolein is easily converted to acrylonitrile, this process likely accounts for only $\sim 5 \%$ of the acrylonitrile formed.

Acetonitrile and hydrogen cyanide are the dominant nitrogen-containing carbon byproducts formed during propene ammoxidation. The selectivity to these products increases with increasing ammonia and oxygen partial pressures, but is not very sensitive to propene conversion or the partial pressure of water vapor, and decreases with increasing temperature. We hypothesize that two different reaction mechanisms are important for the formation of acetonitrile and hydrogen cyanide - one involving addition of an adsorbed $\mathrm{NH}_{3}$ across the $\mathrm{C}-\mathrm{C}$ bond of allylamine to form methylamine and ethenamine, and one involving reaction of allylamine with surface $\mathrm{O}$ resulting in $\mathrm{C}-\mathrm{C}$ bond scission. Since the observed ratio of $\mathrm{HCN}$ to acetonitrile ratio is a constant 5:2, in either case, the intermediates undergo additional attack by $\mathrm{NH}_{3}$.

The reaction mechanism shown in Scheme 1 was proposed to account for all observed products and byproducts, and was used to build a model of the kinetics of product formation as a function of reactant and product partial pressures and temperature. With the rate parameters given in Table 5, this model provides a reasonably good description of the effects of reaction 
conditions on the distribution of products. The model also reveals that to achieve high yields of acrylonitrile, it is desirable to operate at high temperatures, low partial pressures of ammonia, and low partial pressures of oxygen. These conditions minimize the formation of acetonitrile and hydrogen cyanide, but increase the intrinsic selectivity to acrolein. However, conversion of the later product to acrylonitrile via secondary reaction is highly favorable, especially at higher propene conversions. Our work also shows that addition of moderate partial pressures of water vapor to the feed can significantly suppress the wasteful consumption of ammonia to $\mathrm{N}_{2}$, while having only a very minimal effect on the carbon product distribution.

6. Acknowledgements. This work was supported by the Director, Office of Science, Office of Basic Energy Sciences, and by the Division of Chemical Sciences, Geosciences, and Biosciences of the U.S. Department of Energy at LBNL under Contract No. DE-AC02-05CH11231. Theoretical calculations were performed with the resources of the Molecular Graphics and Computation Facility at the University of California, Berkeley under National Science Foundation grant CHE-0840505. The authors would like to acknowledge Dr. Joseph Gomes with his help with the DFT calculations. The authors would also like to acknowledge Prof. T. Don Tilley, Dr. Andrew "Bean" Getsoian, Dr. Gregory Johnson, Dr. Edwin Yik, James Dombrowski, and Micah Ziegler for useful discussions.

\section{References}

[1] J.D. Idol, U.S. Patent 2,904,580 (1959).

[2] J.F. Brazdil, Acrylonitrile, Ullmann's Encyclopedia of Industrial Chemistry, Wiley-VCH, Weinheim, 2007. 
[3] R.K. Grasselli, Top. Catal. 21 (2002) 79-88.

[4] M. Egashira, K. Matsuo, S. Kagawa, T. Seiyama. J. Catal. 58 (1979) 409-418.

[5] W. Ueda, K. Asakawa, C.-L. Chen, Y. Moro-Oka, T. Ikawa, J. Catal. 101 (1986) 360-368.

[6] A.B. Getsoian, Z. Zhai, A.T. Bell, J. Am. Chem. Soc. 136 (2014) 13684-13697.

[7] J.F. Brazdil, L.C. Glaeser, R.K. Grasselli, J. Phys. Chem. 87 (1983) 5485-5491.

[8] B. Grzybowska, J. Haber, J. Janas, J. Catal. 49 (1977) 150-163.

[9] J.D. Burrington, R.K. Grasselli, J. Catal. 59 (1979) 79-99.

[10] H.E. Swift, J.E. Bozik, J.A. Ondrey J. Catal. 21 (1971) 212-224.

[11] C.R. Adams, T.J. Jennings, J. Catal. 3 (1964) 549-558.

[12] L.D. Krenze, G.W. Keulks, J. Catal. 61 (1980) 316-325.

[13] J. Haber, B. Grzybowska, J. Catal. 28 (1973) 489-505.

[14] J.D. Burrington, C.T. Kartisek, R.K. Grasselli, J. Catal. 81 (1983) 489-498.

[15] T.A. Hanna, Coord. Chem. Rev. 248 (2004) 429-440.

[16] A.B. Getsoian, V. Shapovalov, A.T. Bell, J. Phys. Chem. C 117 (2013) 7123-7137.

[17] C.C. McCain, G. Gough, G.W. Godin, Nature 198 (1963) 989-990.

[18] W.M.H Sachtler, N.K. DeBoer, Proceedings $3^{\text {rd }}$ International Congress on Catalysis, 1 (1965) 252.

[19] J.D. Burrington, C.T. Kartisek, R.K. Grasselli, J. Org. Chem. 46 (1981) 1877-1882.

[20] P. Mars, D.W. van Krevelen, Chem. Eng. Sci. 3 (1954) 41-59.

[21] G.W. Keulks, J. Catal. 19 (1970) 232-235.

[22] T.P. Snyder, C.G. Hill, Cat. Rev. 31 (1989) 43-95.

[23] J.M. Peacock, A.J. Parker, P.G. Ashmore, J.A. Hockney, J. Catal. 15 (1969) 398-406.

[24] C. R. Adams, H.H. Voge, C.Z. Morgan, W.E. Armstrong, J. Catal. 3 (1964) 379-386. 
[25] G.W. Keulks, L.D. Krenze, Proceedings $6^{\text {th }}$ International Congress on Catalysis p. 806 (1976).

[26] Z. Zhai, A.B. Getsoian, A.T. Bell, J. Catal. 308 (2013) 25-36.

[27] J.L. Callahan, R.K. Grasselli, E.C. Milberger, H.A. Strecker, Ing. Eng. Chem. Prod. Res. Dev. 2 (1970) 134-142.

[28] R.D. Wragg, P.G. Ashmore, J.A. Hockey, J. Catal. 31 (1973) 293-303.

[29] I.K. Kolchin, S.S. Bobkov, L. Ya. Margolia, Neftekhimiya 4 (1964) 301-307.

[30] C.R. Adams, T.J. Jennings, J. Catal. 2 (1963) 63-68.

[31] K. Aykan, J. Catal. 12 (1968) 281-290.

[32] J. D. Burrington, C.T. Kartisek, R.K. Grasselli, J. Catal. 66 (1980) 347-367.

[33] J.D. Burrington, C.T. Kartisek, R.K. Grasselli, J. Catal. 87 (1984) 363-380.

[34] Y.H. Jang, W.A. Goddard III, J. Phys. Chem. B 106 (2002) 5997-6013.

[35] Y. Du, A.L. Rheingold, E.A. Maatta, J. Am. Chem. Soc. 114 (1992) 345-346.

[36] H.H. Fox, K.B. Yap, J. Robbins, S. Cai, R.R. Schrock, Inorg. Chem. 31 (1992) 2287-2289.

[37] G. Hogarth, I. Richards, Transition Met. Chem. 35 (2010) 111-115.

[38] S. Pudar, J. Oxgaard, K. Chenoweth, A.C.T. van Duin, W.A. Goddard III, J. Phys. Chem. C 111 (2007) 16405-16415.

[39] S. Pudar, J. Oxgaard, W.A. Goddard III, J. Phys. Chem. C 114 (2010) 15678-15694.

[40] I. Matsuura, J. Catal. 33 (1974) 420-433.

[41] M.T. Le, W.J.M. Van Well, I. Van Driessche, S. Hoste, Appl. Catal. A: Gen. 267 (2004) 227-243.

[42] F. Theobald, A. Laarif, Mat. Res. Bull. 20 (1985) 653-665.

[43] S. Grimme, Chem. Eur. J. 18 (2012) 9955-9964. 
[44] B.A. De Moor, M.-F. Reyniers, G. B. Marin, Phys. Chem. Chem. Phys. 11 (2009) 29392958.

[45] A.B. Getsoian, A.T. Bell, J. Phys. Chem. C 117 (2013) 25562-25578.

[46] J. D. Burrington, C.T. Kartisek, R.K. Grasselli, J. Catal. 75 (1982) 225-232.

[47] J. D. Burrington, C.T. Kartisek, R.K. Grasselli, J. Catal. 63 (1980) 235-254.

[48] L. Lietti, G. Ramis, G. Busca, F. Bregani, P. Forzatti, Catal. Today 61 (2000) 187-195. 

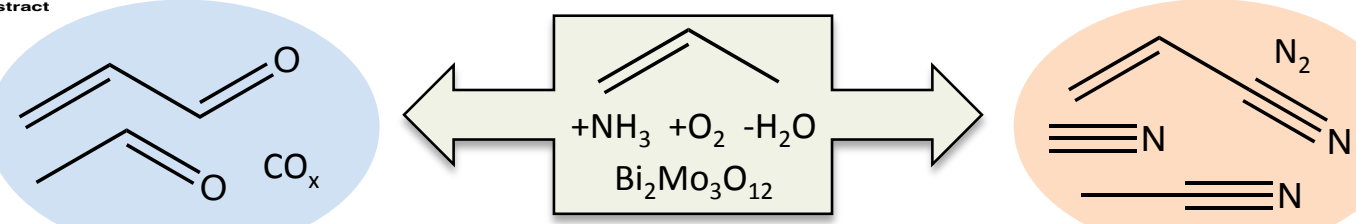

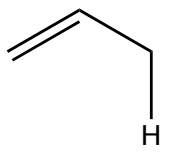

${ }^{\mathrm{O}}{ }_{\mathrm{MO}_{\mathrm{O}}}=\mathrm{O}$
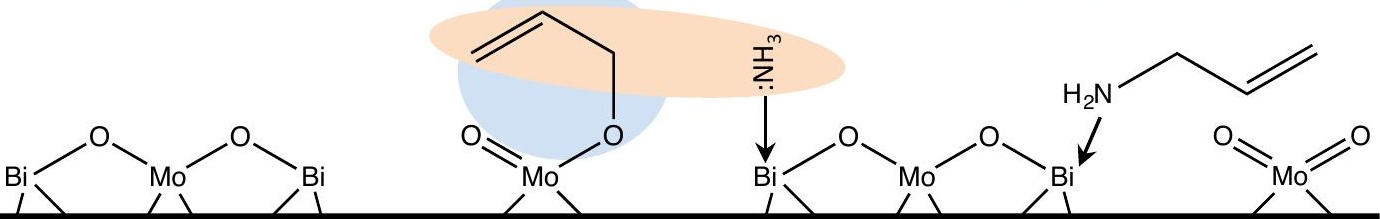